\title{
Patently Non-Obvious: Empirical Demonstration that the Hindsight Bias Renders Patent Decisions Irrational
}

\author{
GREGORY N. MANDEL*
}

This Article reports an experimental study that provides the first empirical demonstration of the hindsight bias in patent law. The results are dramatic along several fronts: (1) the hindsight bias distorts patent decisions far more than anticipated, and to a greater extent than other legal judgments; (2) jury instructions that explicitly identify and warn against the hindsight bias do not ameliorate its impact; (3) the admission of secondary consideration evidence does not cure the hindsight bias; (4) neither the Federal Circuit's suggestion test nor the Supreme Court's Graham requirements appear to resolve the hindsight problem; and (5) the hindsight problem pervades patent law to an extent not previously recognized-it biases decisions under the doctrine of equivalents, claim construction, the on-sale bar, and enablement.

These findings run counter to the dominant patent analysis of the last decade and have significant implications for patent and innovation policy. The study results indicate that the non-obvious requirement actually often may be applied too stringently. Numerous critics of the current non-obvious requirement may need to reconsider the bases of their challenges and revisit their prescriptions for reform. Revising non-obvious doctrine or practice, for instance, may not provide the panacea that many assume. This Article concludes with recommendations for changes in patent doctrine and litigation to mitigate the impact of the hindsight bias.

* (c) 2006 Gregory N. Mandel. Associate Dean for Research \& Scholarship and Professor of Law, Albany Law School. I am grateful to David Adelman, Chris Guthrie, Mark Lemley, Douglas Lichtman, Alyson Mandel, and Jeffrey Rachlinski for their very helpful comments on earlier drafts of this Article. Giovanna D'Orazio provided outstanding research assistance. 


\section{TABLE OF CONTENTS}

I. INTRODUCTION

II. HINDSIGHT BIAS IN THE NON-OBVIOUS ANALYSIS

A. Patent Validity and the Non-Obvious Requirement

B. The Hindsight Bias 1400

C. The Hindsight Bias in the Non-Obvious Analysis 1403

III. HINDSight BIAS IN PATENT LAW EXPERIMENTAL STUDY 1406

A. Method .1406

B. Results 1409

1. Non-Obvious 1409

2. Debiasing Instructions 1410

3. Confidence in Non-Obvious Judgment 1410

4. Likelihood of Invention 1411

C. Discussion .1411

1. Jury Hindsight Bias. .1414

2. Judicial Hindsight Bias 1416

3. PTO Examiner Hindsight Bias 1418

IV. Patent LaW's FaILURE to Ameliorate the Hindsight Bias 1420

A. Secondary Consideration Evidence .1421

B. Prior Art in the Non-Obvious Analysis 1425

1. Combined Reference Non-Obvious Determinations 1426

2. Single Reference Non-Obvious Determinations 1431

3. The Non-Obvious Landscape 1432

C. The Presumption of Validity. 1437

V. Hindsight Bias Throughout Patent LaW 1438

A. Doctrine of Equivalents ......................................................1438

B. Claim Construction .................................................................1440

C. On-Sale Bar .........................................................................1441

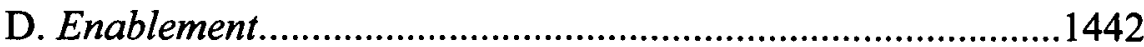

E. Hindsight Bias in Patent Law............................................1443

VI. Solving THE Non-Obvious Hindsight Blas DilemMA ............1444

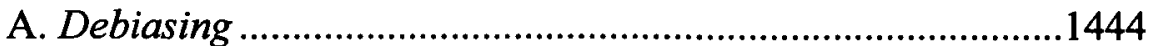

B. Debiasing Patent Law and Litigation .................................1447 


\section{INTRODUCTION}

Imagine a world in which multi-billion dollar intellectual property rights - rights affecting the world's largest firms, markets, and industriesare assigned randomly. A world in which ownership of new invention depends not on innovation or on merits established by rule of law, but rather occurs stochastically and often in direct contradiction to the law. That world is here.

The experimental study reported in this Article provides the first empirical demonstration of the hindsight bias in patent law. The results are dramatic: the hindsight bias prejudices patent decisions far more than anticipated. Not only are patent decisions routinely and unintentionally made in contradiction to patent doctrine, but even more significantly, patent law itself is incoherent. Judges, jurors, and patent examiners seemingly lack the cognitive ability to make decisions in the manner that patent law currently requires.

The core requirement for obtaining a patent is that the invention was not obvious at the time it was invented. Only significant technological advances merit award of a patent. The reasons for the non-obvious requirement are evident: trivial advances will be achieved without the necessity of a patent incentive, and trivial advances do not benefit society enough to warrant imposing the costs of a patent monopoly on the public. Though the nonobvious requirement sounds logical, as applied it is irrational.

Proper non-obvious determinations are unachievable because they require the use of hindsight. The decision should turn on whether the invention was non-obvious in the ex ante world just prior to the invention's creation. A proper non-obvious decision must not take into account the ex post fact that the invention was actually achieved. The present study, however, reveals that people are cognitively incapable of making such an evaluation properly. Rather, decision-makers unconsciously let knowledge of the invention bias their conclusion concerning whether the invention was obvious in the first instance. These findings are supported by other studies in behavioral economics and cognitive psychology outside the patent context. ${ }^{1}$ Individuals are intellectually incapable of preventing hindsight information

${ }^{1}$ See infra Part II.B. 
from impacting their judgments about the past. Individuals routinely (and unconsciously) overestimate what would have been anticipated in foresight and tend to view what actually occurred as having been relatively inevitable and foreseeable.

The hindsight bias is recognized in common wisdom: "hindsight is 20/20," and being a "Monday morning quarterback" exaggerates one's foresight. The hindsight effect is also treated in law. For instance, it is the basis for concern that knowledge of a search outcome (whether incriminating evidence was found) will affect judgments concerning whether there was probable cause for the search in the first instance.

The failure of the legal system to correct for the hindsight bias in patent law likely stems in part from a failure to recognize its magnitude, pervasiveness, and unshakable nature. The results presented here indicate that there is a greater hindsight effect for non-obvious determinations than for other legal judgments. In one scenario, based upon an actually litigated patent, approximately one-quarter of mock jurors considered an invention obvious in the foresight condition (the doctrinally accurate analysis), while about three-quarters of mock jurors considered the same invention obvious in hindsight (the condition in which patent decisions and litigation actually occur). This effect (nearly half of the respondents shifted their legal conclusion in hindsight) is greater than that found in other legal hindsight bias studies in areas including negligence, ${ }^{2}$ punitive damages, ${ }^{3}$ and civil rights litigation. ${ }^{4} \mathrm{~A}$ second scenario, based on a different patent case, similarly found a very substantial hindsight bias: approximately one-third of the respondents shifted their conclusion in hindsight.

This Article also reveals that patent hindsight problems are not limited to non-obvious determinations. Hindsight bias also affects decisions under the doctrine of equivalents, claim construction, the on-sale bar, and enablement. As a result, patent law as applied is both unjust (deserving inventors are denied patents and patent scope, and undeserving inventors are awarded

2 See, e.g., Merrie Jo Stallard \& Debra L. Worthington, Reducing the Hindsight Bias Utilizing Attorney Closing Arguments, 22 LAW \& HUM. BEHAV. 671, 679 (1998) (twentyeight percent of mock jurors shifted decision concerning negligence in hindsight); Kim A. Kamin \& Jeffery J. Rachlinski, Ex Post $\neq$ Ex Ante: Determining Liability in Hindsight, 19 LAW \& HUM. BEHAV. 89, 98 (1995); Reid Hastie et al., Juror Judgments in Civil Cases: Hindsight Effects on Judgments of Liability for Punitive Damages, 23 LAW \& HUM. BEHAV. 597, 606 (1999) (thirty-four percent of mock jurors shifted decision concerning negligence in hindsight).

${ }^{3}$ See generally Hastie et al., supra note 2.

${ }^{4}$ Chris Guthrie et al., Inside the Judicial Mind, 86 CORNELL L. REV. 777, 818 (2001) (twenty-four percent of judges shifted decision concerning section 1983 civil rights scenario in hindsight). 
patents and excessive patent scope) and inefficient (inventors likely do not receive the socially optimal incentives to innovate). The consequent impact on competition, predictability, and innovation may be severe.

The judiciary has been aware of the potential danger of the hindsight problem in non-obvious determinations for some time, and has instituted various jurisprudential tools in an effort to ameliorate its impact. For instance, courts evaluate secondary consideration evidence and require a preexisting suggestion, teaching, or motivation in order to combine prior art references in a non-obvious analysis. Neither of these fixes, however, successfully mitigates the hindsight bias. Briefly, secondary consideration evidence frequently is not available and is not very reliable. Analysis of eighteen months' worth of Federal Circuit and District Court non-obvious decisions reveals that secondary considerations appear to affect only a small percentage of non-obvious decisions, an influence too low to counteract the hindsight bias. The requirement of a suggestion to combine references has been criticized by numerous entities, including the Federal Trade Commission, the National Academy of Sciences, and many patent scholars. ${ }^{5}$ This Article also concludes (though not for the same reasons) that the suggestion test does not resolve the hindsight bias.

Jury instructions that explicitly identify and warn against the hindsight bias also fail to mitigate its effect. The present studies each included a condition in which mock jurors were warned of the hindsight bias and instructed to guard against it in a manner based on Model Jury Instructions. The explicitly warned jurors did not display a statistically lower hindsight bias than the jurors who received no warning. Similarly, the presumption of validity that adheres to issued patents is not intended to remedy the hindsight problem and does not do so. The hindsight bias remains unresolved in existing patent law and practice.

These findings run counter to the dominant scholarly and policy patent analyses of the last decade. A nearly unchallenged chorus now calls for tightening lenient patent standards, particularly the non-obvious

5 Fed. Trade Comm'n, to Promote Innovation: The Proper Balance of COMPETITION AND PATENT LAW AND POLICY, ch. 4, at 12-15 (2003), available at http://www.ftc.gov/os/2003/10/innovationrpt.pdf; NATIONAL RESEARCH COUNCIL OF THE National ACAdemics, A PATENT System For the 21 St Century 90 (Stephen A. Merrill et al. eds., 2004) [hereinafter NATIONAL RESEARCH COUNCIL]; Brief of TwentyFour Intellectual Property Law Professors as Amici Curiae, KSR Int'l Co. v. Teleflex Inc., No. 04-1350, cert. granted, (U.S. June 26, 2006), available at http://patentlaw.typepad.com/patent/ksramicus.pdf (brief of twenty-four intellectual property professors arguing for overturning the suggestion requirement) [hereinafter IP Professors' Amici Brief]; infra note 185. 
requirement. ${ }^{6}$ The results of this study indicate, however, that the nonobvious requirement actually often may be applied too stringently. This has significant implications for patent and innovation policy. Critics of the current non-obvious requirement will need to reconsider the bases of their challenges, and likely need to revisit the contours of their prescriptions for reform. Revising non-obvious doctrine or practice, for instance, may not provide the panacea that many assume.

Part II of this Article provides an introduction to patent law, the hindsight bias, and how the hindsight bias impacts non-obvious decisions. Part III presents the results of the study, revealing a significant hindsight bias among mock jurors. Analysis of the results and existing scholarship indicates that actual jurors, judges, and patent examiners are prone to the hindsight bias to an extent significantly greater than anticipated. Part IV demonstrates

${ }^{6}$ See, e.g., Fed. TRADE COMM'N, supra note 5, ch. 4, at 8-19 (criticizing a low standard for application of the non-obvious requirement and citing the testimony of many patent and economic scholars for the same); NATIONAL RESEARCH COUNCIL, supra note 5, at 87-95 (criticizing lenient non-obvious standards, particularly for business method and biotechnology patents); IP Professors' Amici Brief, supra note 5, at 10 (brief of twenty-four intellectual property law professors arguing that Federal Circuit case law sets too low a non-obvious standard); ADAM B. JAFFE \& JOSH LERNER, INNOVATION AND ITS DISCONTENTS: HOW OUR BROKEN PATENT SYSTEM IS ENDANGERING INNOVATION AND Progress, AND What To do ABOUt IT 32-35, 75, 119-23, 145-49 (2004) (criticizing the PTO for granting patents on obvious inventions); W. Lesser \& Travis Lybbert, Do Patents Come too Easy?, 44 IDEA 381 (2004) (noting a common belief that the nonobvious standard is too low, though arguing based on empirical study that patentability standards have not declined over time); John H. Barton, Non-Obviousness, 43 IDEA 475, 498 (2003) (arguing that obvious patents are being granted); Mark A. Lemley and David W. O'Brien, Encouraging Software Reuse, 49 STAN. L. REV. 255, 301 (1997) (criticizing PTO leniency in issuing obvious patents in software); John Thomas, Collusion and Collective Action in the Patent System: A Proposal for Patent Bounties, 2001 U. ILL. L. REV. 305 (discussing problems at the PTO in conducting non-obvious analyses); Carl Shapiro, Patent System Reform: Economic Analysis and Critique, 19 BERKELEY TECH. L.J. 1017, 1018 (2004) (noting that complaints regarding the PTO "typically allege that the [PTO] issues many questionable patents" including those that were "obvious at the time the patent application was filed"); Edited \& Excerpted Transcript of the Symposium on Ideas into Action: Implementing Reform of the Patent System, 19 BERKELEY TECH. L.J. 1053, 1056 (2004) (comment by Mark Myers, calling for "[r]einvigorat[ion of] the nonobvious standard" and noting that panelists "believe that there has been some lowering of the bar of that standard"); Robert P. Merges, As Many as Six Impossible Patents Before Breakfast: Property Rights for Business Concepts and Patent System Reform, 14 BERKELEY TECH. L.J. 577, 598 (1999) (noting that "[t]he easiest way to raise standards [at the PTO], conceptually, is to tighten the nonobviousness requirement of section 103," but acknowledging that this would be difficult); Ashley N. Parker, Problem Patents: Is Reexamination Truly a Viable Alternative to Litigation?, 3 N.C. J.L. \& TECH. $305,305-07$ (2002) (arguing that the PTO has recently granted a number of obvious patents). 
why existing jurisprudence directed at ameliorating the hindsight bias is inadequate. The previously unidentified impact of the hindsight bias on several patent law doctrines is examined in Part V. Part VI presents recommendations to ameliorate the hindsight problem in patent law. The Article concludes with a discussion of the implications of these results on debates over the non-obvious standard and calls for patent law reform.

\section{HINDSIGHT BIAS IN THE NON-OBVIOUS ANALYSIS}

\section{A. Patent Validity and the Non-Obvious Requirement}

In order to obtain a patent, an inventor must satisfy five validity requirements: subject matter, utility, novelty, non-obviousness, and adequate disclosure. ${ }^{7}$ The subject matter and utility requirements present minimal hurdles. Subject matter concerns the types of invention that are patenteligible. The Patent Act delineates four broad areas of eligible subject matter: processes, machines, manufactures, and compositions of matter. ${ }^{8}$ The Supreme Court has interpreted this eligibility extremely broadly, holding that "anything under the sun that is made by man" is patent-eligible. ${ }^{9}$ Utility similarly presents a minimal standard-it does not require that the invention be better than previous subject matter, only that the invention provides "some identifiable benefit." 10 The vast majority of inventions easily satisfy the subject matter and utility validity requirements.

Novelty entails a variety of intricate rules, but in essence boils down to the requirement that the invention not have been previously patented, published, known or used by others, in public use, or on sale. ${ }^{11}$ An invention is novel unless the prior patent, publication, or use concerned subject matter that contained each and every element of the invention. ${ }^{12}$ The novelty

735 U.S.C. $\S \S 101-03,112$ (2000 \& Supp. 2004).

835 U.S.C. $\$ 101$ (2000). This section also explicitly includes "any new and useful improvement" upon an invention in one of these four categories as proper subject matter. Id.

9 Diamond v. Chakrabarty, 447 U.S. 303, 309 (1980).

10 Juicy Whip, Inc. v. Orange Bang, Inc., 185 F.3d 1364, 1366 (Fed. Cir. 1999) ("The threshold of utility is not high: An invention is 'useful' under section 101 if it is capable of providing some identifiable benefit."). Utility issues most commonly arise where an invention has no known use other than being useful for further research. See Brenner v. Manson, 383 U.S. 519 (1966) (holding that a new process for making a known steroid was not useful where a use of the steroid had not yet been identified, although the steroid was being researched for possible tumor-inhibiting effects).

1135 U.S.C. § 102 (Supp. 2002).

12 Cont'l Can Co. v. Monsanto Co., 948 F.2d 1264, 1267 (Fed. Cir. 1991). 
requirement bars some patent applications, but most applications contain at least one element that distinguishes them from a single prior reference.

Adequate disclosure comprises several requirements concerning what an inventor must disclose in a patent application in order to receive a patent. For instance, it requires that the disclosure enable others to practice the invention, and to practice it in the best mode known to the inventor. ${ }^{13}$ Like novelty, adequate disclosure concerns do arise, but in the majority of circumstances the inventor has control over disclosing the invention sufficiently..$^{14}$

The non-obvious requirement thus emerges as the most critical and core patent validity requirement. ${ }^{15}$ It is the requirement that mandates that inventions contribute more than a trivial advance in order to be entitled to a patent. ${ }^{16}$ The importance of the non-obvious requirement is demonstrated by the reality of patent litigation - the non-obvious requirement is both the most commonly litigated patent validity issue and is the patent validity requirement most likely to result in a patent being held invalid. ${ }^{17}$

1335 U.S.C. $\$ 112$ (2000).

${ }^{14}$ But see Gregory N. Mandel, The Generic Biologics Debate: Industry's Unintended Admission that Biotech Patents Fail Enablement, 12 VA. J.L. \& TECH (forthcoming 2006) (discussing that inventors may not be capable of fully enabling certain complex medical biologic inventions).

${ }^{15}$ IP Professors' Amici Brief, supra note 5, at 3 ("[T]he requirement of nonobviousness is the sole provision that fully implements the core notion of patent law that patents should be granted only for significant advances over previously known technology."); NONOBVIOUSNESS - THE ULTIMATE CONDITION OF PATENTABILITY (John F. Witherspoon ed. 1980). From an incentive to innovate perspective, patents arguably should only issue for inventions that would not have been achieved "but for" the patent incentive. See FED. TRADE COMM'N, supra note 5, ch. 4, at 6 (discussing the "but for" test as a means to harmonize patent law with competition policy). Under this view, the non-obvious requirement is an imperfect proxy for the theoretically optimal patent standard, a standard that cannot be implemented in practice. See id., at 7 ("application of the 'but for' principle generally will not work in individual cases."). Studying how nonobvious determinations and "but for" determinations diverge is worthy of further study.

1635 U.S.C. $\S 103(2000)$.

17 John R. Allison \& Mark A. Lemley, Empirical Evidence on the Validity of Litigated Patents, 26 AIPLA Q.J. 185, 208-09 (1998); see also GLORIA K. KOENIG, PATENT INVAlidity: A STATISTICAL AND SUBSTANTIVE ANALYSIS 5-50 (rev. ed. 1980) (finding that obviousness was the most common basis for judicial invalidation of patents for the period 1953-1978); P.J. Federico, Adjudicated Patents, 1948-54, 38 J. PAT. OfF. SoC'Y 233, 247-48 (1956) (finding that obviousness was the most common basis for judicial invalidation of patents for the period studied). Obviousness was litigated in 160 out of 300 patent validity decisions issued in the almost eight-year period of Allison and Lemley's study; the second most common issue (section 102 prior art) was litigated in only about half as many decisions. Allison \& Lemley, supra at 209. Obviousness was a basis in nearly half (42\%) of all cases in which a patent was held invalid. Id. at 208. 
The non-obvious requirement provides that a patent shall not issue for an invention if "the differences between the subject matter sought to be patented and the prior art are such that the subject matter as a whole would have been obvious at the time the invention was made to a person having ordinary skill in the art to which said subject matter pertains." 18 The Patent Act does not define the term "obvious," and neither the Supreme Court nor the Federal Circuit--the federal appeals court with jurisdiction over most patent appeals-has ever done so either. ${ }^{19}$

The non-obvious standard of $\S 103(\mathrm{a})$ requires the decision-maker to make an historical judgment: whether the invention would have been obvious at the time the invention was made in the past. To reach a proper non-obvious conclusion, the decision-maker must step backward in time to a moment when the invention was unknown. Unfortunately, this mandate is

1835 U.S.C. § 103(a) (Supp. 2004). Prior to the enactment of section 103 in 1952, courts recognized that something more than novelty was required for patentability. In Hotchkiss v. Greenwood, the Supreme Court held:

$[U]$ nless more ingenuity and skill ... were required in [making the claimed invention] ... than were possessed by an ordinary mechanic acquainted with the business, there was an absence of that degree of skill and ingenuity which constitute essential elements of every invention. In other words, the improvement is the work of the skilful mechanic, and not that of the inventor.

52 U.S. 248,267 (1850).

A significant patent reform bill is currently pending in Congress. Patent Reform Act of 2005, H.R. 2795, 109th Cong. (1st Sess. 2005). This bill would not significantly affect the issues discussed here. As proposed, it would revise the non-obvious standard in $\$ 103$ (a) to evaluate obviousness at the time of filing as opposed to the time of invention. Id. Most non-obvious determinations already are based on this time because the filing date is currently treated as the constructive invention date, and an earlier actual invention date usually is not established. In addition, it is the knowledge of invention that produces the hindsight effect, not the length of time between the past date used for non-obvious evaluation and the present. Revising the date for non-obvious evaluation could potentially impact the hindsight effect with respect to the level of skill in the art if that level changed notably between invention and filing.

19 The term "obvious" was introduced in the 1952 Patent Act. 35 U.S.C. $\S 103$ (Supp. 2004). Prior to 1952, courts had read a similar requirement into the term "invention" in the Patent Act. See supra note 18. The Supreme Court held that the 1952 obvious requirement was generally not intended to change the level of patentable invention, but to codify the judicial precedent deriving from Hotchkiss. Graham v. John Deere Co., 383 U.S. 1, 15-17 (1966) (the revision was intended to abolish the "flash of creative genius" test that had been instituted in a later case). Courts have in certain instances stated what "obvious" is not. See infra Part IV. Arguably, the term "obvious" is no better defined or understood than the common law standard it was enacted to replace, a standard that Judge Learned Hand famously critiqued as being "as fugitive, impalpable, wayward, and vague a phantom as exists in the whole paraphernalia of legal concepts." Harries v. Air King Prods. Co., 183 F.2d 158, 162 (2d Cir. 1950). 
more easily stated than achieved. Humans are cognitively incapable of ignoring what they have learned (here, that the invention was achieved), as required for the proper ex ante analysis. Psychologists have studied this phenomenon and have termed it the "hindsight bias."

\section{B. The Hindsight Bias}

In the seminal study on the hindsight bias, Baruch Fischhoff presented subjects with a scenario describing events leading up to an obscure war in India between the British and the Gurkas of Nepal in the early $1800 \mathrm{~s}^{20}$ Subjects were provided with four possible outcomes to the scenario: British victory, Gurka victory, military stalemate with no peace settlement, and military settlement with a peace stalemate. The subjects were divided into five groups. One group was not provided any further information (the foresight condition). The four other groups each received a different additional sentence at the end of the event scenario, indicating that one of the four outcomes had occurred (the hindsight conditions). Subjects were then asked to estimate what the ex ante probability had been for each of the four possible outcomes occurring. ${ }^{21}$

The subjects who were informed that a specific outcome had occurred rated the ex ante probability of that outcome as significantly greater than subjects not informed of any outcome, or subjects informed that a different outcome had occurred. Subjects in the hindsight conditions rated their given outcome as $14.7 \%$ to $23.4 \%$ more likely than subjects in the foresight condition. ${ }^{22}$ This difference reveals the hindsight bias-knowledge of ex post events changes individuals' perception of ex ante likelihood.

In the decades since Fischhoff's experiment, numerous studies have confirmed the existence of the hindsight bias as a robust and widespread cognitive limitation. ${ }^{23}$ These studies demonstrate that the hindsight bias routinely affects both lay and expert judgment in many fields, in both

${ }^{20}$ Baruch Fischhoff, Hindsight $\neq$ Foresight: The Effect of Outcome Knowledge on Judgment Under Uncertainty, 1 J. OF EXPERIMENTAL PSYCHOL.: HUM. PERCEPTION \& PERFORMANCE 288, 289 (1975).

${ }^{21}$ Id.

22 Id. at 291.

${ }^{23}$ See, e.g., Susan J. LaBine \& Gary LaBine, Determinations of Negligence and the Hindsight Bias, 20 LAW \& HUM. BEHAV. 501, 502-04 (1996) (surveying a wide variety of hindsight bias studies); Jay J. J. Christensen-Szalanski \& Cynthia Fobian Willham, The Hindsight Bias: A Meta-Analysis, 48 Organizational Behav. \& Hum. Decision PROCESSES 147 (1991) (meta-analysis of over 120 hindsight bias studies). 
laboratory and applied settings. ${ }^{24}$ Examples involving experts in applied settings include physician medical diagnoses ${ }^{25}$ and supervisor evaluations of employees. ${ }^{26}$ Almost every study that has investigated the hindsight bias has confirmed its existence; a meta-analysis of hindsight bias studies found that 122 out of 128 studies reported a significant hindsight bias effect. ${ }^{27}$

Of import for the focus of this Article, studies of legal judgment outside the context of patent law have found that mock jurors are prone to the hindsight bias. Several experiments have evaluated the hindsight bias in the search and seizure context. Whether incriminating evidence is found during an illegal search should be irrelevant to the legality of the search. Research has found, however, that knowledge of search outcomes (whether incriminating evidence was found) influences mock juror judgments concerning the legality of the search, as well as damage awards in hypothetical suits against police officers for illegal searches. ${ }^{28}$

Tort law raises hindsight concerns as well. Hindsight knowledge that an accident actually occurred should not influence liability judgments about whether appropriate precautions were taken beforehand. In a study concerning appropriate precautions against a flood, three-quarters of participants in foresight believed that a flood was too unlikely to justify precautions, while a majority of hindsight participants believed that such a decision was negligent. ${ }^{29}$ In other tort studies, respondents demonstrated a significant hindsight effect in judging the negligence of therapist decisions

${ }^{24}$ Kamin \& Rachlinski, supra note 2, at 90-91 (citing studies revealing hindsight bias in surgeons' appraisal of surgical cases, physicians' medical diagnoses, women's reactions to pregnancy tests, voters' election predictions, and nurses' employee evaluations).

25 Hal R. Arkes et al., Hindsight Bias Among Physicians Weighing the Likelihood of Diagnoses, 66 J. APPLIED PSYCHOL. 252 (1981).

26 Terence R. Mitchell \& Laura S. Kalb, Effect of Outcome Knowledge and Outcome Valence on Supervisors 'Evaluations, 66 J. APPLIED PsYCHOL. 604 (1981).

27 Christensen-Szalanski \& Willham, supra note 23, at 150-51; see also Jeffrey J. Rachlinski, A Positive Psychological Theory of Judging in Hindsight, 65 U. CHI. L. REV. 571,580 (1998).

28 Dorothy K. Kagehiro et al., Hindsight Bias and Third-Party Consentors to Warrantless Police Searches, 15 LAW \& HuM. BEHAV. 305 (1991); Jonathan D. Casper et al., Juror Decision Making, Attitudes, and the Hindsight Bias, 13 LAW \& HuM. BEHAV. 291 (1989); Jonathan D. Casper et al., Cognitions, Attitudes, and DecisionMaking in Search and Seizure Cases, 18 J. OF APPLIED SOC. PSYCHOL. 93 (1988). A separate study found a hindsight effect in criminal cases where jurors were instructed to disregard information about a prior trial outcome. Galen V. Bodenhausen, SecondGuessing the Jury: Stereotypic and Hindsight Biases in Perceptions of Court Cases, $20 \mathrm{~J}$. APPLIED SOC. PSYCHOL. 1112 (1990).

${ }^{29}$ Kamin \& Rachlinski, supra note 2, at 98-99. 
regarding the clinical treatment of potentially dangerous patients ${ }^{30}$ and in judging the recklessness of a railroad's behavior in relation to an accident. ${ }^{31}$

In short, individuals are not cognitively able to prevent knowledge gained through hindsight from impacting their analysis of past events. Rather, individuals routinely overestimate the ex ante predictability of events after they have occurred. Critical for patent law, once individuals have hindsight information, they consistently exaggerate what could have been anticipated in foresight and not only tend to view what has occurred as having been inevitable, but also as having appeared relatively inevitable beforehand. 32

The hindsight bias appears to be caused by a combination of factors. The most significant factor is cognitive: once an individual learns of an outcome, this (apparently irreversibly) changes the individual's understanding of the world in ways that make the outcome appear inevitable. ${ }^{33}$ The individual automatically projects this new knowledge onto the past and is cognitively challenged in recognizing that it is influencing his or her judgment. ${ }^{34}$ Individuals automatically integrate an outcome and the events that preceded it into a coherent story, which tends to make the antecedents appear more influential and consequential than they are in foresight. ${ }^{35}$ Correspondingly, antecedents that would have indicated alternative outcomes are disregarded as having been inconsequential. ${ }^{36}$ Motivational factors likely also play a role in the hindsight bias: individuals want to see the world as stable and predictable, and they want to be viewed by others as intelligent and perceptive. ${ }^{37}$ Stating or believing that an outcome was predictable satisfies both of these desires.

The hindsight bias has proven remarkably unyielding to varied efforts to ameliorate its impact. Asking individuals to ignore outcome knowledge, formulate the opinion of one unaware of the outcome, or warning them about

30 LaBine \& LaBine, supra note 23. (2002).

31 Cass R. Sunstein ET Al., Punitive Damages: How Juries Decide 103-04

32 Baruch Fischhoff, For Those Condemned to Study the Past: Heuristics and Biases in Hindsight, in JUDGMENT UNDER UNCERTAINTY: HEURISTICS AND BIASES 335, 341 (Daniel Kahneman et al. eds., 1982).

33 Rachlinski, supra note 27, at 582, 584-86.

34 Scott A. Hawkins \& Reid Hastie, Hindsight: Biased Judgments of Past Events After the Outcomes Are Known, 107 PsYCHOL. BULL. 311 (1990).

35 Rachlinski, supra note 27 , at 584.

36 Id.

${ }^{37} I d$. at 582-84. 
the dangers of the hindsight bias does not significantly reduce its impact. ${ }^{38}$ Similarly, various motivational techniques, such as suggesting that individuals try harder or rewarding them for unbiased responses, do not lessen the bias. ${ }^{39}$ These and other debiasing techniques are discussed further below. ${ }^{40}$ Once individuals are aware of an outcome, they are cognitively unable to discount or ignore that knowledge; they no longer can view prior events objectively. ${ }^{41}$

\section{The Hindsight Bias in the Non-Obvious Analysis}

Because the non-obvious validity requirement requires a decision-maker to make an ex ante judgment (whether the invention was obvious at the time it was made) after having received ex post information (that the invention was achieved), hindsight bias is expected to impact the analysis.

Most hindsight research evaluates the bias's impact on probability estimates (as in Fischhoff's British-Gurka experiment). The non-obvious determination, on the other hand, concerns a qualitative judgment rather than a quantitative probability estimate. Probability analyses are of limited assistance in the non-obvious context because a change in probability does not indicate how likely an individual is to change his or her mind in response to a binary question. A small change in probability can have a dramatic impact on responses to binary qualitative decisions that are a close call, but little impact on binary decisions that are viewed as clear-cut.

Some hindsight research does concern qualitative judgments and may be particularly relevant to the non-obvious analysis. First, a number of studies have asked respondents if they "would have known" that a certain outcome would occur, given certain events. This presents not only a binary question, but also frames the question in a manner that likely makes it especially

38 Fischhoff, supra note 32 , at 343 ; Fischhoff, supra note 20 , at 295 . Requiring individuals to argue against the inevitability of the reported outcome (i.e., trying to convince oneself that it might have turned out otherwise) is one debiasing strategy that is partially successful. Fischhoff, supra note 32, at 343.

${ }^{39}$ Kamin \& Rachlinski, supra note 2, at 92.

40 See infra Part VI.A. One tort study in particular reported significant but not a complete reduction of the hindsight bias through particular debiasing efforts. Stallard \& Worthington, supra note 2.

41 See David A. Schkade \& Lynda M. Kilbourne, Expectation-Outcome Consistency and Hindsight Bias, 49 Organizational Behav. \& HuM. Decision Processes 105, 108 (1991) (noting that once an outcome is known, "it becomes difficult to accurately reconstruct a previous state of mind"). 
apropos to the non-obvious issue. ${ }^{42}$ A meta-review of these "would have known" studies found that the hindsight bias could cause as much as twentyseven percent of a population to change its mind on binary decisions in the context most appropriate for non-obvious decisions. ${ }^{43}$

Second, as discussed, some hindsight research has evaluated the impact of the hindsight bias on certain qualitative legal judgments. These studies have simulated juror conclusions regarding defendant culpability, defendant liability for negligence, and whether a warrantless police search constituted an illegal search. ${ }^{44}$ Each of these questions involves a binary, qualitative judgment pursuant to a legal standard, similar to the non-obvious determination. Each study revealed that decision-makers were significantly influenced by the hindsight bias. ${ }^{45}$

Hindsight bias research has revealed that individuals tend to overestimate both the likelihood of a known outcome occurring and the foreseeability of that outcome. ${ }^{46}$ Both biases will impact the non-obvious determination. Overestimating the likelihood of a known invention occurring will tend to make the invention appear obvious. Perhaps even more powerfully, the tendency to overestimate the foreseeability of the invention will make the invention appear to have been more obvious than it actually was. ${ }^{47}$

42 Rachlinski, supra note 27, at 581 n.34 (noting that the "would have known" studies are the most relevant to legal determinations).

43 Christensen-Szalanski \& Willham, supra note 23, at 159-61 (statistic based on unfamiliar determinations concerning events that did occur). As discussed, the average percentage of a population to change its mind on a binary question due to the hindsight bias cannot be calculated because the percentage will vary depending on the decision threshold (i.e., it will vary depending on whether the decision was a close call or clearcut).

44 See supra Part II.B.

45 Kamin \& Rachlinski, supra note 2, at 91, 99.

46 See generally Rachlinski, supra note 27 . It is possible that different psychological mechanisms underlie the traditional hindsight bias that affects quantitative probability judgments versus the effects on qualitative judgments of obviousness (and foreseeability) discussed here. $I d$. at 593 ("No one has conducted a careful study of exactly what makes an outcome seem 'foreseeable' as opposed to 'predictable."'). Such a difference, however, has not been demonstrated, and the mechanisms underlying the hindsight bias (e.g., that learning information irreversibly changes one's understanding of the world to make an outcome appear inevitable, and that individuals want the world to be predictable and want to appear perceptive) do not suggest significant difference.

47 The hindsight bias appears to result from at least three different types of hindsight effects. Mark Kelman, Decomposing Hindsight Bias, 16 J. RISK \& UNCERTAINTY 251 (1998). One type concerns individuals' incorrect beliefs that their ex post judgments would be similar to their ex ante ones. A second concerns the projection of this first effect onto a third party. The third concerns ex post adjustments in the perceived 
Potentially further biasing the non-obvious analysis is that it actually requires two hindsight determinations: first, whether the invention was obvious at the time it was made and second, the past level of ordinary skill in the art. Because the skill level of a person having ordinary skill in the art (a "PHOSITA") increases over time, individuals are expected to consider historic PHOSITAs to be more skilled than they actually were due to the hindsight bias. Such attribution will tend to make inventions appear more obvious than they were. Because of this dual effect, non-obvious determinations may exhibit a greater hindsight bias than other hindsight judgments.

Moderator variables that have been found to influence the extent of hindsight bias have implications for patent law as well. First, the hindsight bias tends to be stronger where an outcome is unexpected. ${ }^{48}$ For patent determinations, this would indicate that the more surprising an invention is, the greater the hindsight bias. Greater technological advances may be subject to a greater hindsight bias than lesser accomplishments. ${ }^{49}$ Second, the bias tends to be greater where an event has occurred (as opposed to evaluating the ex ante probability of an event that is known not to have occurred).$^{50}$ All non-obvious determinations concern evaluating an outcome where an event (the invention) has occurred. Third, the bias tends to be stronger where the evaluative task is unfamiliar to the evaluator. ${ }^{51}$ Effectively all jurors and district court judges (who individually each hear few patent cases) are not

probability that an event would occur. The third type of hindsight sometimes will not be a bias at all, but may reveal proper Bayesian probability adjustment. The former two types are biases-they are errors of judgment. Id. A certain amount of the non-obvious hindsight effect could reflect proper Bayesian adjustment, but the hindsight problem in the non-obvious determination appears most similar to the first type-a true error in recognizing the relationship between ex ante and ex post judgments. The results of the present study confirm that the non-obvious hindsight problem is not the result of proper Bayesian inference. See infra Part III.C.

48 Schkade \& Kilbourne, supra note 41, at 105.

49 This counterintuitive indication does not mean that greater advances would be more likely to be held obvious than lesser advances, but that the degree to which the hindsight bias operates in evaluating greater advances (i.e., the degree to which the nonobvious nature of the advance is discounted) will be stronger for these advances than for lesser breakthroughs.

50 Christensen-Szalanski \& Willham, supra note 23 , at 155 . This meta-analysis found that the effect size of the hindsight bias increased from $r=.16$ for event not occurring to $r=.22$ for event occurring for unfamiliar tasks. Id.

51 Christensen-Szalanski \& Willham, supra note 23 , at 155 . The meta-analysis found that the effect size of the hindsight bias increased from $r=.16$ for familiar tasks overall to $r=.22$ for unfamiliar tasks where an event has occurred. Id. The complexity of the evaluation, on the other hand, does not appear to influence the impact of the hindsight bias. Kamin \& Rachlinski, supra note 2, at 91. 
expected to be familiar with evaluating non-obviousness. Patent examiners, on the other hand, will be familiar with the task. Non-obvious determinations thus appear to fall generally into classes that are particularly susceptible to the hindsight bias.

In sum, prior to this study, a variety of circumstantial evidence indicated that non-obvious decisions are subject to a hindsight bias.

\section{HINDSIGHT BIAS IN PATENT LAW EXPERIMENTAL STUDY}

Despite the critical import of the hindsight bias for patent decisions, its impact has not previously been tested. This Part presents the empirical results of original experimental research conducted to evaluate the impact of the hindsight bias on non-obvious determinations.

The study addresses the following hypotheses: (1) hindsight knowledge that an invention was achieved will increase an individual's judgment of the obviousness of the invention; (2) debiasing instructions will not diminish the effect of the hindsight bias; (3) hindsight information will not influence an individual's confidence in his or her judgment of the obviousness of an invention; and (4) hindsight information will increase an individual's judgment of the ex ante likelihood of an invention.

\section{A. Method}

Participant mock jurors were given a hypothetical fact scenario concerning an invention. 52 The scenario included background information about the field of art of the invention, a variety of prior art reference information, a description of the problem that a person cast in the role of the inventor was working on, and a questionnaire. The participants were newly matriculated law students during orientation (first-year classes had not begun). Participation was voluntary; 247 participants returned completed questionnaires. ${ }^{53}$

The scenarios were each based loosely on the facts of actual issued patents that were challenged on non-obvious validity grounds in litigation and were the subject of a reported decision. The scenarios were selected for inventions that would be easy for mock jurors to comprehend (to reduce the

52 The scenarios are described below and full versions are included in Appendix A.

53 The precise number of participants who were given the scenario is unknown. There were approximately 250 students attending orientation. Although it appeared that every student in the room at the time of the study completed and returned the questionnaire, it is possible that several did not. 
need for significant material on the skill level of a PHOSITA) ${ }^{54}$ and for inventions that presented apparently disputable questions of nonobviousness. ${ }^{55}$ The inventions, prior art, and facts were modified in part from the actual cases in order to meet these and other practical concerns. A pilot study was run using three different scenarios. One of the scenarios generated several participant questions concerning its clarity and was dropped from the final study.

The two scenarios used in the study concerned baseball instruction and fishing lures. The baseball scenario involved instructional materials for teaching people how to throw different baseball pitches. ${ }^{56}$ The prior art described in the scenario included instructional videos showing how to hold and release different pitches, articles and books which described how to hold and release different pitches, cards which showed a picture of a hand holding a baseball in the proper way to make a certain pitch, plastic baseballs with indentations showing how to hold the ball to make a certain pitch, and baseball workshops where people could go to learn different pitches. The inventor was an individual who develops new baseball instruction material for a sporting goods company. He was asked to develop a new pitching instruction product that allowed the student to actually hold a real baseball while learning how to throw a pitch, but that did not require individual, oneon-one instruction.

The fishing lure scenario involved an avid fisherman and lure-maker who was trying to produce an artificial fishing lure that would have a salty flavor but would not lose the flavor or spoil in water. ${ }^{57}$ The prior art included the following: an article titled "Touch Up Your Lures" that suggested adding fish attractants with the flavor or odor of natural bait to lures; a patent on a lure made out of squirrel hair with yeast and salt baked in so as to emit an odor attractive to fish; The Great Book of Black Bass, which noted that fish could actually "taste" bait before biting, and recommended the use of salted pork rind as bait; and an entry entitled "Salted Wonder for Trout" in the Field Sports Almanac that described using salted minnows as bait, noting, "real monster trout will take salt-flavored minnows as if they are

54 In this manner, this study imitated the Supreme Court's decision in Graham, where the Court instituted the PHOSITA analysis, and then implicitly applied its own (lay) understanding of what a person having ordinary skill in the art would know. Graham v. John Deere Co., 383 U.S. 1 (1966).

55 This latter condition was sought by selecting cases in which the court's nonobvious analysis indicated that the result was not entirely clear.

56 This scenario was based on the facts of McGinley v. Franklin Sports, Inc., 262 F.3d 1339, 1343-47 (Fed. Cir. 2001).

57 This scenario was based on the facts of Arkie Lures, Inc. v. Gene Larew Tackle, Inc., 119 F.3d 953, 954-55 (Fed. Cir. 1997). 
going out of style." Additional information, including certain difficulties attendant to the problems, was provided in each scenario.

To assess the impact of the hindsight bias without biasing individual responses, a between-subjects experimental design was used. ${ }^{58}$ Each participant received only a single scenario in one of three different conditions. The foresight condition (or control condition) included all of the lead-up information and ended with the scenario character trying to solve the identified problem. The hindsight condition was identical to the foresight condition except that it had one additional sentence at its end which stated that the character had come up with a solution, and stated what the solution was. The debiasing condition was identical to the hindsight condition, but the questions following the scenario included instructions based on Model Patent Jury Instructions that informed the participant of the hindsight problem, warned him or her about it, and advised him or her not to use hindsight in answering the questions. ${ }^{59}$

Participants were asked three substantive questions in the questionnaire portion of the study. These questions asked: (1) whether, in light of the prior art and information provided in the scenario, a solution to the problem was obvious to a person with ordinary skill in the relevant field ("yes" and "no" answer spaces were provided); ${ }^{60}(2)$ the confidence the respondent had in his or her answer to the obvious query (answered on a scale from $0 \%$ to $100 \%$ with answers indicated in $10 \%$ increments); and (3) the likelihood that the inventor in the scenario would achieve the invention (answered on a scale from 1-"not at all likely" to 7-“extremely likely").

Because the only thing that varied between the foresight and hindsight conditions was the presence of information concerning achievement of the invention (that is, because all other factors were controlled for), any

58 See David W. Martin, DoIng Psychology EXPERIMENTS 150-53, 172 (6th ed. 2004) (discussing benefits of a between-subjects experimental design).

59 The hindsight instructions stated: "In answering this question, you should avoid using hindsight: that is, you should not consider that [the inventor] came up with a solution, or what [the inventor's] solution was, in determining whether it was obvious at the time [the inventor] was working on it." These instructions were modeled on the Federal Circuit Bar Association's MODEL PATENT JURY INSTRUCTIONS, http://www.fedcirbar.org/documents/forms/LINKS/\%20FED.\%20CIR.\%20FINAL\%20VERSION\%20(3).PDF, and the American Intellectual Property Law Association's MODEL JURY INSTRUCTIONS, http://www.aipla.org/Content/ContentGroups/Publications1/Guide_to_Model_Patent_Jur y_Instructions.htm.

${ }^{60}$ For instance, the baseball scenario foresight non-obvious question read, "In light of the existing instructional materials and information in the scenario above, do you think a solution to the problem was obvious to a person with ordinary skill in the field of baseball instruction at the time [the inventor] was working on the problem?" 
differences between the foresight and hindsight groups' responses can be attributed to the presence of this information. Similarly, because the only thing that varied between the hindsight and debiasing conditions was the presence of the debiasing jury instruction, any differences between the hindsight and debiasing groups' responses can be attributed to the presence of this instruction. ${ }^{61}$

B. Results

\section{Non-Obvious}

To test the hypothesis that hindsight knowledge of an invention increases an individual's judgment of the ex ante obviousness of the invention, Fisher's exact test was run to analyze the frequency of obvious and non-obvious responses in the foresight condition and the combined hindsight conditions (both the "hindsight" and the "debiasing" conditions). Separate analyses were conducted for the baseball and fishing lure scenarios.

As expected, participants rated inventions non-obvious significantly more frequently in foresight than in hindsight in both the baseball scenario $\left(X^{2}=25.203\right.$, Fisher's $\left.p<.001\right)$ and the fishing lure scenario $\left(X^{2}=10.623\right.$, Fisher's $p<.01)$. Descriptive statistics are presented in Table 1. For the baseball scenario, 24\% (10 out of 42) of participants in the foresight condition thought that a solution to the problem was obvious, while $71 \%$ (59 out of 83) of participants in the combined hindsight conditions thought that a solution was obvious (see Table 1). Results were similar for the fishing lure scenario: $23 \%$ (9 out of 40 ) of participants in the foresight condition thought that a solution to the problem was obvious, while $54 \%$ (44 out of 82 ) of those in the combined hindsight conditions thought that a solution was obvious (see Table 1).

\section{Table 1. Participant Responses}

\begin{tabular}{|l|l|c|c|c|c|}
\hline \multicolumn{2}{|c|}{} & $\mathrm{n}$ & $\begin{array}{c}\text { Obvious } \\
\text { (frequency) }\end{array}$ & $\begin{array}{c}\text { Confidence } \\
\text { (mean) }\end{array}$ & $\begin{array}{c}\text { Likelihood } \\
\text { (mean) }\end{array}$ \\
\hline \multirow{3}{*}{ Baseball } & foresight & 42 & $10(24 \%)$ & 65.48 & 4.40 \\
& hindsight & $42^{\mathrm{a}}$ & $32(76 \%)$ & 75.71 & 5.41 \\
& debiasing & 41 & $27(66 \%)$ & 70.98 & 5.00 \\
\hline \multirow{3}{*}{ Fishing Lure } & foresight & 40 & $9(23 \%)$ & 72.00 & 4.05 \\
& hindsight & 41 & $24(59 \%)$ & 66.34 & 4.66 \\
& debiasing & 41 & $20(49 \%)$ & 67.32 & 4.49 \\
\hline
\end{tabular}

a One baseball hindsight participant did not answer the likelihood question.

61 See Andrew J. Wistrich et al., Can Judges Ignore Inadmissible Information? The Difficulty of Deliberately Disregarding, 153 U. PA. L. REV. 1251, 1284 (2005) (stating similar conclusions based on the control versus test groups in their study). 


\section{Debiasing Instructions}

To test the impact of the debiasing instructions on non-obvious judgments, Fisher's exact test was run to analyze the frequency of nonobvious responses across the hindsight and debiasing conditions. As expected, debiasing instructions had no significant effect on judgments of obviousness in both the baseball scenario $\left(X^{2}=1.079\right.$, Fisher's $\left.p=n s\right)$ and the fishing lure scenario $\left(X^{2}=.785\right.$, Fisher's $\left.p=n s\right)$. Combining the hindsight and debiasing data across both scenarios similarly demonstrated no significant effect of debiasing instructions $\left(X^{2}=1.813\right.$, Fisher's $\left.p=n s\right)$. Participants were no more likely to consider an invention non-obvious in the debiasing condition than they were in the hindsight condition.

\section{Confidence in Non-Obvious Judgment}

Analysis of variance was used to assess the hypothesis that hindsight information is not expected to influence individuals' confidence in their judgment of the obviousness of an invention. Results showed no overall significant effect of hindsight knowledge of invention on participants' confidence in their non-obvious judgments for both the baseball scenario $\left(F_{(d f=1,122)}=3.041, n s\right)$ and the fishing lure scenario $\left(F_{(d f=1,119)}=.963, n s\right)$.

Analysis of variance was also conducted isolating those individuals (in both foresight and hindsight) who judged an invention non-obvious, and separately those who judged an invention obvious. Results showed no overall significant effect of hindsight knowledge of invention for participants who judged an invention non-obvious for both the baseball scenario $\left(F_{(d f=1,54)}=.542, n s\right)$ and the fishing lure scenario $\left(F_{(d f=1,67)}=.511, n s\right)$. Results showed an overall significant effect of hindsight knowledge of invention for participants who judged an invention obvious for the baseball scenario $\left(F_{(d f=1,67)}=7.564, p<.01\right)$, but not for the fishing lure scenario $\left(F_{(d f=1,51)}=3.860, n s\right)$. Results of post hoc analyses on baseball scenario participants who judged the invention obvious revealed that participants in the combined hindsight conditions were more confident in their judgments of obviousness $(M=78.1)$ than participants in the foresight condition $(M=64.0)$. Participants in the debiasing condition $(M=77.8)$ did not differ in confidence ratings from participants in the hindsight condition $(M=78.4)$. Results' reported in other studies have found no difference in confidence ratings between participants in foresight and hindsight conditions. ${ }^{62}$

62 See, e.g., Ed Bukszar \& Terry Connolly, Hindsight Bias and Strategic Choice: Some Problems in Learning from Experience, 31 ACAD. OF MGMT. J. 628, 637 (1988). 


\section{Likelihood of Invention}

Analysis of variance was used to assess the hypothesis that hindsight knowledge of invention will increase an individual's judgment of the ex ante likelihood of the invention. As expected, there was an overall significant effect of hindsight knowledge of an invention on participants' ratings of the ex ante likelihood of invention for the baseball scenario $\left(F_{(d f=2,121)}=8.196, p<.001\right)$. Results of post hoc analyses for the baseball scenario revealed that participants in the foresight condition $(M=4.40)$ responded that solving the problem was significantly less likely than participants in the hindsight condition $(M=5.41 ; t=-4.024, p<.001)$, and that participants in the debiasing condition $(M=5.00)$ did not differ from participants in the hindsight condition $(t=1.643, n s)$. Although there was no overall significant effect of hindsight knowledge on participants' likelihood ratings in the fishing lure scenario $\left(F_{(d f=2,119)}=2.669, n s\right)$, results of post hoc analyses revealed that participants in the foresight condition $(M=4.05)$ responded that solving the problem was significantly less likely than participants in the hindsight condition $(M=4.66 ; t=-2.243, p<.05)$, and participants in the debiasing condition $(M=4.49)$ did not differ from participants in the hindsight condition $(t=.633, n s)$.

\section{Discussion}

The results demonstrate that the hindsight bias significantly influences non-obvious judgments. Participants who were not informed of the invention were substantially more likely to judge a solution non-obvious than participants who were informed what the invention was. The magnitude of the hindsight bias in these patent scenarios was striking and is greater than that reported for other legal judgments. ${ }^{63}$ Ex post knowledge of invention deeply affected participants' conclusions regarding whether an invention was non-obvious ex ante.

Equally significant, debiasing instructions based on actual model jury instructions did not ameliorate the hindsight bias. This finding is consistent

63 The hindsight bias shifted the decisions of about one-half and about one-third of the mock jurors in the baseball and fishing lure scenarios, respectively. Studies of the hindsight bias in other legal judgments have found that $24 \%$ to $34 \%$ of mock jurors or judges shifted their judgments. Guthrie et al., supra note 4, at 818 (24\% of judges shifted decision in section 1983 scenario in hindsight); Hastie et al., supra note 2, at 606 (24\% of mock jurors shifted decision concerning punitive damages in hindsight); Kamin \& Rachlinski, supra note 2, at 98 (34\% of mock jurors shifted decision concerning negligence in hindsight); Stallard \& Worthington, supra note 2, at 679 (28\% of mock jurors shifted decision concerning negligence in hindsight). 
with a study of the hindsight bias in tort law, which found no significant effect from hindsight debiasing instructions. ${ }^{64}$ It is also consistent with a variety of research on jury instructions indicating that the instructions often fail to produce their desired results, that jurors have an extremely low level of recall and comprehension of instructions, and that intended improvements to jury instructions often actually reduce juror understanding. ${ }^{65}$

In addition to the hindsight bias, the study indicates that hindsight condition participants who concluded that an invention was obvious may even be more confident in their answer than foresight participants. This effect was found for the baseball, but not for the fishing lure scenario, although results for the fishing lure scenario were "almost" significant $(p=.055)$. If this effect is valid, it indicates that individuals impacted by the hindsight bias are overconfident in their incorrect judgments, likely rendering mitigation of the bias even more difficult to achieve.

Though the non-obvious hindsight bias revealed in this study is substantial, it may understate the true bias. Participants in the foresight condition are asked whether any solution to the problem is obvious. Participants in the hindsight conditions are asked the same question, but are primed by the nature of the survey to focus on the specific solution produced. It is likely that hindsight participants focus only on the obviousness of the specific invention produced, as opposed to any solution, leading to results that understate the impact of the hindsight bias.

A second reason the current study may understate the actual hindsight bias concerns the level of skill in the art of the fields of invention used in the scenarios. Both fields (baseball instruction and fishing lures) require a relatively low level of skill in the art. They were chosen in part for this purpose-allowing lay participants to understand the PHOSITA skill level and prior art more easily. Most inventions will involve a higher PHOSITA skill level, and one that is more likely to increase over time. As the nonobvious determination requires evaluating obviousness from the perspective of a PHOSITA at the time of invention, there may be an added hindsight bias in judging the past, lower level of ordinary skill in the art. To the extent

${ }^{64}$ Kamin \& Rachlinski, supra note 2, at 99.

65 Gregory Mitchell, Why Law and Economics' Perfect Rationality Should Not Be Traded for Behavioral Law and Economics' Equal Incompetence, 91 GEO. L.J. 67, 134 n.209 (2002); SUNSTEIN, supra note 31, at 90-92; John M. Conley, Epilogue: A Legal and Cultural Commentary on the Psychology of Jury Instructions, 6 PsYCHOL. PUB. POL'Y \& L. 822 (2000) (discussing how the complex effects of jury instructions make it hard to identify the effects of particular reforms); Shari Seidman Diamond, Instructing on Death: Psychologists, Juries, and Judges, 48 AMER. PSYCHOLOGIST 423 (1993); Stanley Sue et al., Effects of Inadmissible Evidence on the Decisions of Simulated Jurors: $A$ Moral Dilemma, 2 J. APPLIED SOC. PSYCHOL. 345 (1973). 
ordinary skill in the art has evolved since the time of invention, the hindsight bias may be exacerbated beyond the findings reported here.

The manifestation of the hindsight effect for low skill in the art inventions also demonstrates that this effect is the result of a true hindsight bias and not simply the result of appropriate Bayesian adjustment. ${ }^{66}$ For high skill arts, where decision-makers have a hard time understanding the field, information that a particular invention was achieved could lead the decisionmaker to rationally conclude that the solution may actually have been more obvious than it appeared. This could reflect proper Bayesian inference. For low skill arts, where decision-makers are better able to understand the field, however, a significant hindsight effect indicates that a true cognitive bias is the cause. ${ }^{67}$

The results of this study are limited by several factors. The study relied on an abstraction of a non-obvious decision. Mock jurors were given a short scenario and brief instructions, and were asked only for individual responses. In practice, non-obvious determinations are made by juries, judges, and Patent and Trademark Office (PTO) examiners. In actual jury patent litigation for instance, a jury would receive a greater wealth of evidence, plaintiff's and defendant's opposing viewpoints, extensive judicial instruction, and be asked to form a group decision. Each of these factors could ameliorate or exacerbate the hindsight bias. The real-world decision making of judges and PTO examiners differs from the study format as well. The variety of earlier studies on the hindsight bias and on legal judgment in a diversity of circumstances, however, indicates that the "greater seriousness" of actual settings would not significantly change the outcome. Increased information, motivation, and incentives, for example, do not mitigate the hindsight bias. ${ }^{68}$ The following discussion provides an analysis of existing empirical evidence on the potential effect of the hindsight bias on juries, judges, and PTO examiners in light of the instant study. The analysis

66 See Kelman, supra note 47, at 251 (discussing the difference between actual hindsight bias and Bayesian probability adjustment).

${ }^{67}$ See supra Part II.C; see also Kelman, supra note 47, at 258 (identifying individuals' incorrect beliefs that their ex post judgment will be similar to their ex ante judgment as a true error of judgment).

68 See infra Part VI.A. Greater detail can actually make the hindsight bias worse. Rachlinski, supra note 27, at 576. See Guthrie et al., supra note 4, at 819-21 (discussing a variety of reasons why experimental hindsight bias studies are expected to extrapolate to courtroom decision making). One study, in particular, did find that defense counsel arguments could help ameliorate, but not eliminate, the hindsight bias. See infra Part VI.A. 
reveals that all non-obvious decision-makers are expected to be significantly impacted by the bias. ${ }^{69}$

\section{Jury Hindsight Bias}

In a jury trial, the jury deliberates regarding a non-obvious verdict. Deliberation could have significant implications on the impact of the hindsight bias - the bias may operate in a different manner in a group setting than it does in the individual situation tested here..$^{70}$ Understanding the effect of the hindsight bias on jury decision making is crucial-over seventy percent of all patent trials are held before juries. ${ }^{71}$

The effect of group decision making processes on cognitive biases raises issues at the intersection of behavioral economics and social psychology. In general, studies of these interactions reveal complex relations without simple trends - group decision making can exacerbate or ameliorate biases in ways that are not yet well understood. ${ }^{72}$ Two types of group decision making studies, however, are particularly relevant here: studies on jury deliberation and studies on the hindsight bias in groups.

The primary relevance of jury deliberation studies for the hindsight bias is the manner in which juries aggregate individual positions to reach a verdict. Empirical evidence indicates that on issues which present binary questions, jury decision making seems to follow a majority rule. A representative study in this regard examined the relationship between jury results and initial individual juror views in a punitive damage awards scenario. ${ }^{73}$ The study found that juror deliberation decisions were consistent with a simple majority-rule principle when deciding whether to award punitive damages at all. ${ }^{74}$ This result is consistent with other jury

${ }^{69}$ Experimental investigation of the effect of the hindsight bias on actual or mock juries, actual judges, and actual PTO examiners are areas worthy of further study.

70 David Schkade et al., Deliberating About Dollars: The Severity Shift, 100 ColuM. L. REV. 1139, 1164-67 (2000); see generally James H. Davis et al., Effects of Group Size and Procedural Influence on Consensual Judgments of Quantity: The Example of Damage Awards and Mock Civil Juries, 73 J. PERSONALITY \& SOC. PSYCHOL. 703 (1997).

71 JAFFE \& LERNER, supra note 6, at 123.

72 Norbert L. Kerr et al., Bias in Judgment: Comparing Individuals and Groups, 103 PSYCHOL. REV. 687, 692-93 (1996).

73 SUNSTEIN, supra note 31, at 43-44.

74 Id. at 43; see also Schkade et al., supra note 70, at 1153 (reporting on the same study). Juror decisions on other, non-binary issues in the punitive damages study did not always represent majority rule. Among juries that decided to award punitive damages, the researchers found a significant severity shift in the award: where the median of predeliberation individual judgments favored a large award, deliberation typically 
deliberation studies and actual juror interviews. ${ }^{75}$ As the non-obvious decision presents a binary question, a reasonable best estimate is that juries will follow a majority rule when deciding this issue. Statistically, this would mean that jury verdicts would be just as susceptible to the hindsight bias as individual judgment.

A pair of studies has investigated the relationship between the hindsight bias in individuals and in groups. ${ }^{76}$ Both of these studies approximate the relationship between juror and jury in the non-obvious context. The first study investigated the hindsight bias in a same-subjects design in which groups reached judgments after individual judgments had already been recorded. ${ }^{77}$ The hindsight bias was found to be equally large in the individual and group judgment conditions. ${ }^{78} \mathrm{~A}$ second study investigated individual versus group hindsight bias in situations in which the hindsight participants were asked to make judgments " as if they had not known the outcome." 79 Individuals and groups displayed "robust" hindsight effects that were statistically identical. ${ }^{80}$

Group decision making may ameliorate some cognitive biases, but does not appear to reduce the hindsight bias. ${ }^{81}$ Juries are expected to be just as impacted by the hindsight bias as individuals in the context of non-obvious decisions, and just as incapable of disregarding the information that an invention was achieved.

increased the dollar award, often dramatically. Over one-quarter of the deliberating juries awarding punitive damages reached punitive awards as great or greater than the highest individual juror's pre-deliberation judgment. Schkade et al., supra note 70, at 1154-56; SUNSTEIN, supra note 31 , at 43-44.

75 Davis et al., supra note 70 , at 704 ("[B]oth laboratory studies of mock juries and interviews of actual ex-jurors have reported that ... the initial majority tend[s] to determine [the] verdict" (citations omitted)).

${ }^{76}$ Apparently, no study has investigated the relationship between the hindsight bias for individuals and for groups in the jury context.

${ }^{77}$ Bukszar \& Connolly, supra note 62 , at $635,637$.

78 Id.

79 Dagmar Stahlberg et al., We Knew It All Along: Hindsight Bias in Groups, 63 Organizational BehaV. \& HuM. Decision Processes 46, 49 (1995).

${ }^{80} \mathrm{Id}$. at 52 . Other experiments in this study found that groups had a better recall ability than individuals. Id. at 55. This indicates that groups will demonstrate a lesser hindsight bias where the task is recall of an earlier judgment. Such an advantage does not exist in contexts without a prior judgment, as in non-obvious determinations.

${ }^{81}$ Id. at 48, 52. 


\section{Judicial Hindsight Bias}

If jurors and juries are expected to suffer from a significant hindsight bias in deciding non-obvious issues, perhaps judges can do better. Unfortunately, the empirical evidence indicates otherwise.

A study of every patent validity decision issued over an eight-year period indicates that judges are as equally prone to hindsight bias as juries. This study did not find a statistically significant difference between the rate at which judges and juries held patents invalid for obviousness. ${ }^{82}$ Were judges less impacted by the hindsight bias, one would expect judges to hold patents invalid for obviousness at a lower rate than juries. ${ }^{83}$

Guthrie, Rachlinski, and Wistrich conducted a study of the susceptibility of 167 federal magistrate judges to various cognitive biases. ${ }^{84}$ Their study reveals that judges demonstrate less susceptibility to certain cognitive illusions but not to the hindsight bias. ${ }^{85}$ Judicial judgments exhibited "hindsight bias to the same extent as mock jurors and other laypersons." 86 These authors also identify a number of published opinions in which the decision explicitly reveals hindsight bias in judicial decision making. ${ }^{87}$ These results are consistent with other findings that judges exhibit a hindsight bias. 88

82 Allison \& Lemley, supra note 17 , at 214-15. Although the difference was not significant, judges did conclude that an invention was obvious more frequently than juries did. $I d$.

83 The similarity in the rates at which judges and juries hold inventions invalid for obviousness does not definitively prove that each is equally affected by the hindsight bias. It is possible that one group is less affected by the hindsight bias, but has some countervailing bias that causes it to invalidate patents for obviousness at the same rate. Such a countervailing bias has not been identified.

84 Guthrie et al., supra note 4.

85 Id. at 778.

$86 \mathrm{Id}$. at 803,818 .

$87 \mathrm{Id}$. at 804 . The most extreme example concerns a court holding a trustee liable for failing to sell stock before the stock market crash of 1929. In re Chamberlain, 156 A. 42, 42 (N.J. Prerog. Ct. 1931). The court reasoned that "[i]t was common knowledge, not only amongst bankers and trust companies, but the general public as well, that the stock market condition at the time of [the] testator's death was an unhealthy one, that values were very much inflated, and that a crash was almost sure to occur." Id. at 43.

88 John C. Anderson et al., Evaluation of Auditor Decisions: Hindsight Bias Effects and the Expectation Gap, 14 J. ECON. PSYCHOL. 711, 725-30 (1993). A separate pair of related studies found that judges were somewhat less susceptible to the hindsight bias than others. Hastie et al., supra note 2, at 906; W. Kip Viscusi, How Do Judges Think About Risk?, 1 AM. L. \& ECON. REV. 26, 29 (1999). These results, however, have been criticized for being biased because "the sample of judges in these studies (those who chose to attend a conference on law and economics) and the context within which the 
A later study by the same researchers was designed to test whether judges' knowledge of a search outcome created a hindsight bias concerning probable cause for the search. ${ }^{89}$ This study found no statistically significant hindsight effect. ${ }^{90}$ In the words of the authors, "These results are somewhat surprising. The vast literature on the hindsight bias includes virtually no studies that fail to uncover evidence of the hindsight bias." 91 The authors suspect that judges actually are not basing probable cause assessments on probability but on socially appropriate police conduct. ${ }^{92}$ Supporting this analysis, follow-up data reveals a juciicial hindsight bias concerning probability estimates of the likelihood of searches to produce incriminating evidence. ${ }^{93}$

The meta-analysis of hindsight bias studies discussed earlier identified one moderator variable that could indicate that judges will perform better than jurors. Individuals familiar with a task, either because they have experienced it or because they are an expert in an area relevant to the task, demonstrate slightly less of a hindsight bias than individuals who are unfamiliar with the task. ${ }^{94}$ The magnitude of the improvement, however, is small; the effect size of the hindsight bias for those familiar with the task was only 0.2 standard deviation units less than for those unfamiliar with the task. ${ }^{95}$

Even this modest improvement, however, may be too much to expect. Judges likely cannot be considered to be "familiar" with non-obvious determinations. The average district judge receives only a few patent cases per year and hears only one patent trial every seven years. ${ }^{96}$ Many of these

study took place (a law and economics conference) may have induced somewhat more calculated reasoning processes that dampened the [hindsight] effect." Guthrie et al., supra note 4 , at 818 n. 201.

89 Wistrich et al., supra note 61 , at 1313.

$90 \mathrm{Id}$. at 1316.

91 Id. at 1317.

92 Id.

93 E-mail from Jeffrey Rachlinski, Professor of Law, Cornell Law School, to Gregory N. Mandel, Associate Professor of Law, Albany Law School (Nov. 22, 2005) (on file with author).

94 Christensen-Szalanski \& Willham, supra note 23, at 155.

$95 \mathrm{Id}$. This calculation is based on data for conditions in which an event did occur, the condition most appropriate for the non-obvious determination. See infra note 103 and accompanying text for a discussion of the effect of a 0.2 standard deviation unit difference.

${ }^{96}$ Neil E. Graham, Specialized Patent Trial Court, Judges, Debated at House Hearing on Patent Reform, 70 BNA'S PAT., TRADEMARK, \& COPYRIGHT J. 657, 657 (2005) (citing the testimony of Kimberly A. Moore and John B. Pegram before the House Subcommittee on Courts, the Internet, and Intellectual Property). 
cases will not involve a non-obvious issue. ${ }^{97}$ District court judges generally will not be familiar with non-obvious determinations. ${ }^{98}$

The existing evidence indicates that judges will be equally susceptible to the hindsight bias as jurors when judging non-obviousness. The judicial probable cause study, however, reveals that this effect may not always have a straightforward impact on judicial decision making. Further study is warranted.

\section{PTO Examiner Hindsight Bias}

The finding that familiarity with the task reduces the hindsight bias holds more promise for PTO examiners. PTO examiners are experts in their fields (many hold Ph.D.'s in relevant areas), and they keep abreast of scientific developments in their areas. ${ }^{99}$ The average PTO examiner evaluates more than one hundred patent applications each year, ${ }^{100}$ most of which will have to be evaluated to determine whether they are non-obvious. PTO examiners will generally be familiar with both the technology surrounding an invention and with the non-obvious task.

Consequently, PTO examiners are expected to demonstrate less of a hindsight bias than judges or jurors. However, as noted, this familiarity improvement is likely slight: those familiar with a task reveal only 0.2 standard deviation units less of a hindsight bias effect size than those unfamiliar with the task. ${ }^{101}$ The effect of this improvement on a population will vary depending on how the population is distributed-whether it is about evenly split on obviousness or more one-sided in its judgment. ${ }^{102}$ The greatest effect would occur for a population that is evenly split on the issue, in which case a 0.2 standard deviation unit change would still represent less

97 About one-half of reported patent validity decisions include a non-obvious issue. Allison \& Lemley, supra note 17, at 246. Many patent trials do not involve validity issues, but only infringement, damages, or other claims.

98 One could argue that even though district court judges only rarely hear nonobvious issues, their familiarity with other judicial decision making provides expertise in this regard. Hindsight judgments, for instance, are required in other contexts, most prominently in negligence cases. Though both negligence and non-obvious decisions involve hindsight judgments based on an objective, imaginary person (the reasonable person and the PHOSITA), it is hard to conceive that familiarity with the former provides significant expertise concerning the latter.

99 Rochelle Dreyfuss, Pathological Patenting: The PTO as Cause or Cure, 104 MICH. L. REV. 1559, 1576 (2005).

100 JAFFE \& LERNER, supra note 6, at 131.

101 Christensen-Szalanski \& Willham, supra note 23, at 155.

102 Id. at 156-60. 
than ten percent of the population. ${ }^{103}$ For less evenly split populations, the effect would be far less. ${ }^{104}$ PTO examiners are still expected to be significantly affected by the hindsight bias.

The indication that PTO examiners will be slightly less influenced by the hindsight bias than judges or juries provides some support for the presumption of validity that adheres to a patent upon issuance. Whether and how this burden improves judge and jury non-obvious decisions, however, is questionable. ${ }^{105}$

In sum, the results of the experiment reported here and the existing empirical data indicate that non-obvious decisions, whether by judge, jury, or PTO examiner, are routinely subject to a significant hindsight bias. As a result, patent validity decisions may be both unjust and inefficient. The decisions are unjust to the extent statutorily deserving inventors are denied patents or patent scope because the hindsight bias makes non-obvious inventions appear obvious. ${ }^{106}$ Validity decisions will be inefficient to the extent the improper rejection of patents due to the hindsight bias reduces inventors' incentive to innovate below the socially optimal level. ${ }^{107}$ These conclusions, if unresolved, have powerful implications for patent law,

${ }^{103}$ Less than ten percent of a normally distributed population falls within 0.1 standard deviations of the mean ( 0.1 standard deviation above the mean plus 0.1 below adding up to the 0.2 unit effect size).

104 Where the threshold for a non-obvious determination is not at the mean, the percent of the population affected by the familiarity improvement would be even less, falling to zero for a non-obvious threshold far from the population mean.

${ }^{105}$ See infra Part IV.C.

106 See LON L. FUller, The Morality OF LAW 39 (rev. ed. 1969) (stating that the rule of law is violated when there is incongruence "between the rules as announced and their actual administration").

${ }^{107}$ The inefficiency conclusion is qualified as it rests on several assumptions. First, that Congress was not aware of the effect of the hindsight bias on patent validity decisions or was not aware that attempted doctrinal cures were ineffective. If Congress were aware, it arguably may intentionally have set the non-obvious standard "too high," recognizing that it would effectively be lowered in application. Considering the complete absence of any legislative or other history indicating that the non-obvious bar was artificially inflated, this assumption seems safe.

The second (and more questionable) assumption is that the non-obvious standard enacted by Congress is efficient. Many critics argue that it is not. See infra note 260 . If, for instance, patent law as enacted provides too strong an incentive for inventors, the reduction in incentive created by the hindsight bias may actually improve efficiency. The efficiency of incentives offered by patent law is a likely unanswerable question and is beyond the scope of this Article. Even if this second assumption is inappropriate, the hindsight bias still results in patent decisions that create incentives for inventors significantly different from those intended by Congress. 
innovation, and competition, and therefore for the economy and society as a whole.

\section{PATENT LAW's Failure to Ameliorate the Hindsight Bias}

This study provides the first empirical demonstration of the hindsight bias in patent law. The Supreme Court and Federal Circuit have suspected this problem for some time (though not its magnitude or persistence) and have tried to develop case law to guard against it. ${ }^{108}$ Under the Supreme Court's seminal non-obvious decision in Graham and subsequent precedent, the decision-maker (whether judge, jury, or PTO examiner) is expected to avoid letting knowledge that the invention was achieved affect his or her decision about whether it was obvious at the time it was achieved. ${ }^{109}$ The courts have recognized that meeting this standard "requires the oft-difficult but critical step of casting the mind back to the time of invention, to consider the thinking of one of ordinary skill in the art, guided only by the prior art references and the then-accepted wisdom in the field." 110

108 Hindsight problem concerns can be traced back over one hundred years. See, e.g., Loom Co. v. Higgins, 105 U.S. 580, 591 (1882) (noting a concern about judging combination inventions in hindsight: "Now that [the invention] has succeeded, it may seem very plain to any one that he could have done it as well.").

109 Graham v. John Deere Co., 383 U.S. 1, 36 (1966) (stating that courts must "“guard against slipping into use of hindsight"" (quoting Monroe Auto Equip. Co. v. Heckethorn Mfg. \& Supply Co., 332 F.2d 406, 412 (1964))); In re Dembiczak, 175 F.3d 994, 998 (Fed. Cir. 1999) (stating that one must guard against "entry into the "tempting but forbidden zone of hindsight"' (quoting Loctite Corp. v. Ultraseal Ltd., 781 F.2d 861, 873 (Fed. Cir. 1985))).

110 In re Dembiczak, 175 F.3d at 999; see also W.L. Gore \& Assocs., Inc. v. Garlock, Inc., 721 F.2d 1540, 1553 (Fed. Cir. 1983) ("It is difficult but necessary that the decisionmaker forget what he or she has been taught at trial about the claimed invention and cast the mind back to the time the invention was made (often as here many years), to occupy the mind of one skilled in the art who is presented only with the references, and who is normally guided by the then-accepted wisdom in the art.").

Courts and the PTO have sometimes struggled with understanding exactly what the hindsight bias is. The Manual of Patent Examining Procedure, in addressing arguments commonly made by patent attorneys regarding "improper rationales for combining references," notes:

Applicants may argue that the examiner's conclusion of obviousness is based on improper hindsight reasoning. However, "[a]ny judgement [sic] on obviousness is in a sense necessarily a reconstruction based upon hindsight reasoning, but so long as it takes into account only knowledge which was within the level of ordinary skill [in the art] at the time the claimed invention was made and does not include knowledge gleaned only from applicant's disclosure, such a reconstruction is proper." 
The Supreme Court and Federal Circuit have developed two jurisprudential methods in an attempt to combat the effects of hindsight bias: secondary consideration evidence and the requirement of a suggestion, teaching, or motivation to combine elements in prior art in the non-obvious analysis. Each of these jurisprudential fixes is deficient. Similarly, the presumption of validity that adheres to issued patents is not a cure for the hindsight bias. Despite dedicated efforts to neutralize the hindsight bias, current patent doctrine fails to adequately compensate for the effects of the bias on non-obvious determinations.

\section{A. Secondary Consideration Evidence}

The Supreme Court in Graham established specific steps for the nonobvious analysis: (1) determine the scope and content of the prior art; (2) evaluate the differences between the prior art and the claims at issue; and (3) determine the level of ordinary skill in the art.111 "Against this background, the obviousness or non-obviousness of the subject matter is determined."112 These Graham steps provide a subjective analysis of whether an invention was obvious at the time it was made. Objective evidence, termed "secondary consideration" evidence, that an invention was not obvious at the time it was made also may be introduced. ${ }^{113}$ Such secondary consideration evidence could include, for instance, the commercial success of an invention or that the invention filled a long-felt need. Commercial success may indicate an invention was non-obvious because if the invention was obvious, someone else would have invented it in order to capture the potential profits. Longfelt need may indicate that an invention was non-obvious because another individual would have filled that need if there were an obvious way to do so.

The Supreme Court recognized the use of secondary consideration evidence in Graham in an effort to "guard against slipping into use of hindsight." 14 The Federal Circuit subsequently has held that it is "error to exclude [secondary consideration] evidence from consideration." 115 The

Manual of Patent Examining PRocedure $§ 2145(X)(A)$ (7th ed. 1998) (quoting In re McLaughlin, 443 F.2d 1392, 1395 (C.C.P.A. 1971)) (first alteration in original). The hindsight bias problem does not simply arise from consideration of knowledge gleaned from the applicant's disclosure (though this is one potential problem), but from knowledge of the invention itself.

111 Graham, 383 U.S. at 17.

112 Id.

113 Id. at $17-18$.

114 Id. at 36 (quoting Monroe Auto Equip. Co. v. Heckethorn Mfg. \& Supply Co., 332 F.2d 406, 412 (1964)).

115 Stratoflex, Inc. v. Aeroquip Corp., 713 F.2d 1530, 1539 (Fed. Cir. 1983). 
rationale behind secondary consideration evidence is that it may help a decision-maker realize that an invention which appears obvious actually is only obvious in hindsight, and was not obvious at the time it was made. In an effort to achieve this goal, courts have recognized a variety of types of secondary consideration evidence, including: long-felt need, ${ }^{116}$ commercial success, ${ }^{117}$ the failure of others to achieve the invention, ${ }^{118}$ copying by others, ${ }^{119}$ licensing by others, ${ }^{120}$ acclaim from others in the field, ${ }^{121}$ and unexpected results or advantages. ${ }^{122}$

Though secondary consideration evidence was introduced to reduce the impact of the hindsight bias, it fails to accomplish this purpose. Secondary consideration evidence does not significantly ameliorate the hindsight problem for two basic reasons: it is often not available, and even when it is available, it is not particularly probative of whether an invention was nonobvious.

A comprehensive survey of all reported Federal Circuit and district court non-obvious decisions for the eighteen-month period from July 1, 2004 through December 31, 2005 was conducted. This study reveals that secondary consideration evidence is rarely relevant to the non-obvious analysis in reported decisions. Forty-one of the ninety-three $(44 \%)$ nonobvious decisions during this period included secondary consideration evidence. ${ }^{123}$ Fourteen of these forty-one decisions, however, resulted in a holding that the invention was obvious, demonstrating that the secondary consideration evidence could theoretically have been relevant in at most twenty-seven $(29 \%)$ of the cases. This number, however, is deceiving. Analysis of these twenty-seven decisions indicates that secondary consideration evidence was dispositive in only one or two of them (that is, it

116 Ecolochem, Inc. v. S. Cal. Edison Co., 227 F.3d 1361, 1377 (Fed. Cir. 2000).

117 ld. at $1377-78$.

118 Id. at $1378-79$.

$119 \mathrm{Id}$. at 1380 .

120 SIBIA Neurosciences, Inc. v. Cadus Pharm. Corp., 225 F.3d 1349, 1358 (Fed. Cir. 2000).

121 Ecolochem, 227 F.3d at 1380 .

122 Hybritech Inc. v. Monoclonal Antibodies, Inc., 802 F.2d 1367, 1382-83 (Fed. Cir. 1986).

123 See infra Appendix B. The study included decisions at any litigation phase. The inclusion of preliminary injunction and summary judgment decisions could arguably bias the sample in relation to issues that would be presented to a jury (there would not be any difference for judges because the hindsight bias can influence their decision in any trial phase). The rate of secondary consideration evidence in these phases $(55 \%)$ was slightly higher than the overall rate (44\%), indicating that perhaps juries are less likely to receive secondary consideration evidence than judges. 
actually may have caused the court to change from an obvious conclusionpotentially due to the hindsight effect - to a non-obvious conclusion). In the other twenty-five cases, the secondary consideration evidence appears merely to have been used to further support a non-obvious conclusion that would have been reached anyway. One of the two decisions influenced by secondary consideration evidence explicitly found that secondary consideration evidence rebutted what would otherwise have been a finding that an invention was obvious. ${ }^{124}$ A second case can be implicitly read to have considered secondary consideration evidence decisive because the nonobvious analysis is based primarily on unexpected results and copying secondary consideration evidence, rather than the Graham factors. ${ }^{125}$ In sum, secondary consideration evidence appears to rebut what would otherwise have been a holding that an invention was obvious in only one to two percent of reported cases over this eighteen-month period. Though this result may understate the influence of secondary consideration evidence, ${ }^{126}$ the impact appears to be a drop in the bucket compared with the strong effect of the hindsight bias.

The rare influence of secondary consideration evidence may be a blessing. Courts and scholars have repeatedly noted that much secondary evidence is not reliable. Robert Merges, for instance, has concluded that "commercial success is a poor indicator of significant technical advance" because it "can result from a number of factors, only one of which is the technical superiority of the innovation." 127 Commercial success can only

124 Kemin Foods v. Pigmentos Vegetales del Centro, No. 4:02-cv-40327, 2004 U.S. Dist. LEXIS 17737, at *61-64 (S.D. Iowa Sept. 2, 2004).

125 Trading Techs. Int'l, Inc. v. eSpeed, Inc., 370 F. Supp. 2d 691, 694 (N.D. Ill. 2005).

126 The result may understate the true influence of secondary consideration evidence for a couple reasons. First, it is possible that even where a written decision gives no indication that secondary considerations played a role in the decision, such evidence may still have been influential, at either a conscious or subconscious level. Conscious underreporting of secondary consideration evidence seems unlikely; there is no clear reason to deny that it had a role. Unconscious non-reporting is possible, but would be extremely difficult to measure. A second reason that the results may understate the influence of secondary consideration evidence is that cases with definitive secondary consideration evidence that an invention was non-obvious may be expected to settle, biasing the analysis of reported cases. Such a result seems unlikely. Secondary consideration evidence rarely appears so strong as to be dispositive, in part because of the substantial concerns about its reliability discussed in the following text.

127 Robert P. Merges, Commercial Success and Patent Standards: Economic Perspectives on Innovation, 76 CAL. L. REV. 805, 859 (1988); see also FED. TRADE CoMM'N, supra note 5, ch. 4, at 18-19 (arguing that commercial success often is not a valid indicator that an invention was non-obvious). 
demonstrate that an invention was non-obvious if one can establish that (1) the commercial success was due to the non-obvious invention (as opposed to marketing, advertising, market access, product tying, or other factors), (2) the fact that the improvement would be commercially successful was perceived before the invention was achieved, (3) others had perceived this potential commercial success and sought to take advantage of it, and (4) the others failed because the inventor was the first to achieve the invention by a significant time margin. ${ }^{128}$ Long-felt need evidence would require a like number of unlikely inferences in order to actually provide probative evidence that an invention was non-obvious. ${ }^{129}$

Similarly, copying or licensing of an invention by others may result from a variety of factors other than non-obviousness. Copying by others, directly contrary to a non-obvious conclusion, may indicate that the copiers believe that the invention is obvious, and therefore that the copiers would prevail in an infringement lawsuit should the patent owner seek to enforce their patent. ${ }^{130}$ Licensing by others also may be a strategic action. Though a licensee may consider a patent obvious, and likely defeatable in litigation, the licensee may conclude that it is less expensive to license the patented product than to litigate patent validity. ${ }^{131}$ Or, the licensee may desire to maintain a cooperative business relationship with the patent owner. ${ }^{132}$ In most instances, reliance on secondary consideration evidence to establish that an invention was non-obvious risks hindsight bias-hindsight perception that the facts giving rise to the alleged inference arose because the invention was non-obvious and hindsight perception that other individuals would have created the invention themselves if it were obvious.

The failure of other persons having ordinary skill in the art to achieve an invention could be a true indicator that an invention was non-obvious, assuming that the failed efforts were truly directed at the same goal the

128 Edmund W. Kitch, Graham v. John Deere Co.: New Standards for Patents, 1966 SUP. CT. REv. 293, 331-32, reprinted in 49 J. PAT. OfF. SOC'Y 237, 282-83 (1967); see also Ecolochem, Inc. v. S. Cal. Edison Co., 227 F.3d 1361 (Fed. Cir. 2000) (noting that the patent owner must show that the commercial success resulted from the invention).

${ }^{129}$ Merges, supra note 127, at 872; see also Ecolochem, 227 F.3d at 1376-77 (noting that the patent owner must show that the invention was in fact developed in response to the particular long-felt need, and not for some other reason).

${ }^{130}$ Merges, supra note 127 , at $872-73$; see also Ecolochem, $227 \mathrm{~F} .3 \mathrm{~d}$ at 1380 (noting that copying by others and accolades from others are to be given less deference than other forms of secondary consideration evidence because of potential unreliability).

131 Merges, supra note 127, at 866-72.

132 Id. 
invention achieved. ${ }^{133}$ In this instance, the failure of others would provide powerful evidence that an invention was non-obvious.

In order to evaluate the prevalence of reliable secondary consideration evidence, the instant study also investigated the types of secondary evidence available in the eighteen-month sample of non-obvious decisions. Unfortunately, the most common secondary consideration evidence is one of the least reliable: commercial success evidence was introduced in thirtythree percent of the decisions. ${ }^{134}$ The second most common type of secondary evidence is also questionable: long-felt need was noted in twentyfour percent of the decisions. No other type of secondary consideration evidence is identified in more than thirteen percent of the reported decisions. ${ }^{135}$

Secondary consideration evidence appears to affect only a small percentage of non-obvious decisions, and most secondary consideration evidence that is proffered is unreliable (this latter point may account for the former). To the extent secondary considerations do affect non-obvious decisions, they introduce additional concerns, as discussed above. Secondary consideration evidence does not solve the hindsight problem.

\section{B. Prior Art in the Non-Obvious Analysis}

The second manner in which the judiciary has sought to combat the hindsight bias in non-obvious determinations is through a set of case-lawcreated safeguards developed primarily by the Federal Circuit. ${ }^{136}$ These rules seek to guide and limit decision-makers in determining whether an invention is obvious in light of prior art so as to mitigate the impact of the hindsight bias. Evaluation of non-obvious jurisprudence, however, reveals that the safeguards do not resolve the hindsight problem.

Federal Circuit case law separates non-obvious determinations into two types: non-obvious decisions based on combinations of prior art references and non-obvious decisions based on a single reference.

133 Id. at $863,866$.

134 Evidence of commercial success was introduced in seventy-six percent of the decisions that considered any secondary consideration evidence.

135 See infra Appendix B.

136 The Supreme Court has not provided guidance on how to avoid the hindsight bias in the non-obvious determination since Graham. The Court has decided three nonobvious cases since Graham, none of which considered the hindsight bias. See Anderson's-Black Rock, Inc. v. Pavement Salvage Co., 396 U.S. 57, 61 (1969); Dann v. Johnston, 425 U.S. 219, 230 n.4 (1976); Sakraida v. Ag Pro, Inc., 425 U.S. 273, 282-83 (1976). 


\section{Combined Reference Non-Obvious Determinations}

The majority of reported non-obvious decisions concern whether an invention is obvious in light of multiple prior art references. Critical to this analysis is whether such references can be combined in the non-obvious analysis. Combining all references would often allow a decision-maker to pick and choose the elements of an invention from the prior art, and would tend to make almost any invention appear obvious. ${ }^{137}$

In an effort to preclude such an improper result, the Federal Circuit requires that the non-obvious analysis be conducted viewing the invention as a whole. ${ }^{138}$ Using "'hindsight reconstruction to pick and choose among isolated disclosures in the prior art to deprecate the claimed invention"'139 or

137 See Ruiz v. A.B. Chance Co., 357 F.3d 1270, 1275 (Fed. Cir. 2004); Interconnect Planning Corp. v. Feil, 774 F.2d 1132, 1143 (Fed. Cir. 1985). An example I often give my patents class is $3 \mathrm{M}$ Post-It notes. The elements of this invention existed in the prior art: paper and a known adhesive that was seemingly useless because it did not permanently stick. Their combination, however, was not obvious.

${ }^{138}$ Ruiz, 357 F.3d at 1275.

Without [the "as a whole"] requirement, an obviousness assessment might break an invention into its component parts $(A+B+C)$, then find a prior art reference containing $\mathrm{A}$, another containing $\mathrm{B}$, and another containing $\mathrm{C}$, and on that basis alone declare the invention obvious. This form of hindsight reasoning, using the invention as a roadmap to find its prior art components, would discount the value of combining various existing features or principles in a new way to achieve a new result - often the very definition of invention.

Id.; Stratoflex, Inc. v. Aeroquip Corp., 713 F.2d 1530 at 1537 (Fed. Cir. 1983). "[T]he question under 35 U.S.C. $\S 103$ is not whether the differences themselves would have been obvious. Consideration of [the] differences . . . is but an aid in reaching the ultimate determination of whether the claimed invention as a whole would have been obvious." Id: see also MANUAL of PATENT EXAMINING Procedure $\$ 2141$ (7th ed. 1998). The Manual states:

When applying 35 U.S.C. 103, the following tenets of patent law must be adhered to: (A) The claimed invention must be considered as a whole; (B) The references must be considered as a whole and must suggest the desirability and thus the obviousness of making the combination; (C) The references must be viewed without the benefit of impermissible hindsight vision afforded by the claimed invention and (D) Reasonable expectation of success is the standard with which obviousness is determined.

Id. (citing Hodosh v. Block Drug Co., 786 F.2d 1136, 1143 n.5 (Fed. Cir. 1986)). Thus, even though every element of an invention may exist in prior art, the invention as a whole may still be non-obvious. Interconnect Planning Corp., 774 F.2d at 1139-42; Gillette Co. v. S.C. Johnson \& Son, Inc., 919 F.2d 720, 725 (Fed. Cir. 1990). 
conducting a "reference-by-reference, limitation-by-limitation analysis" fails to demonstrate how the invention is obvious in light of prior art. 140 Similarly, the decision-maker may not use the invention as a blueprint for linking together pieces of prior art in order to find the invention obvious. ${ }^{141}$ The Federal Circuit has referred to using the invention as a "blueprint for piecing together the prior art . . . [as] the essence of hindsight." 142

To achieve the related goals of avoiding hindsight bias, viewing the invention as a whole, and not using the invention as a blueprint, the Federal Circuit requires that there must be some "suggestion, teaching, or motivation" in order to combine references in the non-obvious analysis. ${ }^{143}$ The basis for this rule is explicitly to avoid hindsight bias: "The best defense

139 Ecolochem, Inc. v. S. Cal. Edison Co., 227 F.3d 1361, 1371 (Fed. Cir. 2000) (quoting In re Fine, 837 F.2d 1071, 1075 (1988)).

$140 \mathrm{Id}$. at 1374 .

141 Interconnect Planning Corp., 774 F.2d at 1141 ("It is impermissible to first ascertain factually what [the inventor] did and then view the prior art in such a manner as to select from the random facts of that art only those which may be modified and then utilized to reconstruct [the] invention from such prior art.") (quoting In re Shuman, 361 F.2d 1008, 1012 (1966)); Gillette Co., 919 F.2d at 724 (citing Hybritech v. Monoclonal Antibodies, Inc, 802 F.2d 1367, 1383 (Fed. Cir. 1986)); Orthopedic Equip. Co., Inc. v. United States, 702 F.2d 1005, 1012 (Fed. Cir. 1983) ("It is wrong to use the patent in suit as a guide through the maze of prior art references, combining the right references in the right way so as to achieve the result of the claims in suit.").

142 In re Dembiczak, 175 F.3d 994, 999 (Fed. Cir. 1999)

$143 \mathrm{Id}$; see also MANuAl of PATENT EXAMINING PROCEDURe $\S 2143.01$ (7th ed. 1998) ("Obviousness can only be established by combining or modifying the teachings of the prior art to produce the claimed invention where there is some teaching, suggestion, or motivation to do so found either [explicitly or implicitly] in the references themselves or in the knowledge generally available to one of ordinary skill in the art.") (citing In re Fine, 837 F.2d 1071, 1075 (Fed. Cir. 1988); In re Jones, 958 F.2d 347, 351 (Fed. Cir. 1992)). Some decisions substitute other terms for "motivation" in the "suggestion, teaching, or motivation" requirement, such as "reason" or "incentive," but this difference in terminology does not appear to indicate any substantive distinction. See, e.g., Gambro Lundia AB v. Baxter Healthcare Corp., 110 F.3d 1573, 1578-79 (Fed. Cir. 1997) ("the record must provide a teaching, suggestion, or reason to substitute" the patentee's improvement for the disclosure in the prior art); In re Geiger, 815 F.2d 686, 688 (Fed. Cir. 1987) (must be a "teaching, suggestion, or incentive" to combine prior art references).

The Supreme Court recently granted certiorari to consider a challenge to the suggestion test as violating the Patent Act and Supreme Court precedent. KSR Int'l Co. v. Teleflex, Inc., No. 04-1350, 126 S. Ct. 2965 (June 26, 2006). A subsequent experimental study in the current line of research tests the effect of the suggestion test, and the Graham framework, on the hindsight bias in non-obvious decisions. Gregory N. Mandel, Patently Non-Obvious II: Experimental Study on the Hindsight Issue Before the Supreme Court in KSR v. Teleflex, 9 YALE J.L. \& TECH. (forthcoming 2006). 
against the subtle but powerful attraction of a hindsight-based obviousness analysis is [the] rigorous application of the requirement for a showing of the teaching or motivation to combine prior art references."144 The Circuit applies this rule strictly and comprehensively. Thus, it has cautioned that this rule must be adhered to in the selection of the relevant prior art as well as in combining prior art. ${ }^{145}$ The Circuit even applies it where there seems to be a trend in the prior art, and making only minor changes in accordance with the trend appears to lead to the invention. ${ }^{146}$

The suggestion, teaching, or motivation 147 to combine may come from any of three sources: the teachings of the prior art, the nature of the problem to be solved, or the knowledge of persons of ordinary skill in the art. ${ }^{148}$ These bases are discussed in turn.

The teachings of the prior art provide the requisite suggestion to combine references where "there is something in the prior art as a whole to suggest the desirability, and thus the obviousness, of making the combination." 149 A reference does not need to expressly teach a combination, ${ }^{150}$ but the suggestion must be particular, not simply a broad or general statement. ${ }^{151}$ In re Fulton concerned a patent application that claimed a shoe sole with hexagonal shaped projections in a "facing orientation" to increase the sole's resistance to slip. ${ }^{152}$ The Bowerman reference identified a shoe sole with an "open perimeter" around the sole and "cylindrical polygon shaped ... projections" on the sole to provide good traction. 153 Bowerman expressly described square, rectangular, and triangular (but not hexagonal) polygons. ${ }^{154}$ The Pope reference disclosed "a shoe sole with hexagonal surfaces ... and a facing orientation."155 Fulton's shoe sole included the open perimeter of Bowerman and the hexagonal

144 In re Dembiczak, 175 F.3d at 999.

145 Monarch Knitting Mach. Corp. v. Morat, 139 F.3d 877, 881 (Fed. Cir. 1998); In re Rouffet, 149 F.3d 1350, 1357 (Fed. Cir. 1998).

146 Monarch Knitting Mach., 139 F.3d at 881; In re Rouffet, 149 F.3d at 1357.

147 The case law does not appear to draw a distinction between a "suggestion" and a "motivation."

148 Monarch Knitting Mach., 139 F.3d at 881; In re Rouffet, 149 F.3d at 1357.

149 In re Fulton, 391 F.3d 1195, 1200 (Fed. Cir. 2004) (quoting In re Beattie, 974 F.2d 1309, 1311 (Fed. Cir. 1998) (emphasis added)).

150 Motorola, Inc. v. Interdigital Tech. Corp., 121 F.3d 1461, 1472 (Fed. Cir. 1997).

151 In re Dembiczak, 175 F.3d at 999.

152 In re Fulton, 391 F.3d at 1196-97.

$153 \mathrm{Id}$. at 1200.

154 Id.

$155 I d$. 
surfaces and facing orientation of Pope. ${ }^{156}$ The Federal Circuit held that Bowerman provided a teaching to combine it with Pope because Bowerman's patent "clearly suggest[ed] that cylindrical polygon shaped ... projections other than those expressly described" may be used to provide good traction. 157

The nature of the problem to be solved provides a suggestion to combine references where the nature of the problem "would have led a person of ordinary skill in the art to combine the prior art teachings in the particular manner claimed."158 In Pro-Mold \& Tool Co., Inc. v. Great Lake Plastics, Inc., the Federal Circuit held that the nature of the problem to be solved provided sufficient suggestion to select and combine references for a card holder for baseball trading cards. ${ }^{159}$ The problem the invention sought to solve was the creation of a card holder that would fit inside a storage box sized with similar dimensions to a baseball card. ${ }^{160}$ The court held that "the size of the card provided the motivation to combine the features of the prior art card holders" which included a card holder that had a desirable cardholding mechanism but was too large, and another card holder that was substantially the size of a baseball card. ${ }^{161}$

The third potential source for combining prior art references is the "knowledge of persons of ordinary skill in the art."162 The Federal Circuit in In re Rouffet held that the knowledge factor required pointing to a "specific understanding or technological principle" known in the art that would suggest combining the references. ${ }^{163}$ The decision-maker may not simply rely on the level of skill in the art, even if high. ${ }^{164}$ Simply relying on the level of skill in the art to provide the knowledge to combine references, according to the Federal Circuit, was effectively combining the references with the assistance of hindsight. ${ }^{165}$

156 Id. at 1200.

157 Id. at 1199.

158 Teleflex, Inc. v. KSR Int'l Co., 119 F. App'x 282, 288, No. 04-1152, 2005 U.S. App. LEXIS 176, at *16 (Fed. Cir. Jan. 6, 2004) (citing In re Rouffet, 149 F.3d at 1357)).

15975 F.3d 1568, 1573 (Fed. Cir. 1996).

160 Id. at 1571 .

${ }^{161}$ Id. at 1573; see also Ruiz, 357 F.3d at 1276 (holding that a motivation to combine references may be implied from the nature of the problem to be solved, and does not have to appear expressly, for example, in writing in the prior art).

162 In re Rouffet, 149 F.3d 1350, 1357 (Fed Cir. 1998).

163 Id. at 1357-59.

164 Id. Reliance on a high level of ordinary skill in the art would result in all patents in high skill level fields being held obvious. Id.

165 Id. at 1358. 
The Federal Circuit mandates "rigorous application" of the suggestion, teaching, or motivation requirement in an effort to avoid the hindsight bias. ${ }^{166}$ References may only be combined upon a "clear and particular" showing of a suggestion, teaching, or motivation to combine. ${ }^{167}$ In re Dembiczak concerned an invention that was a large trash bag made of orange plastic and decorated with features so that the bag would look like a Halloween pumpkin when filled with trash or leaves. ${ }^{168}$ The Board of Patent Appeals and Interferences held the invention obvious in light of a combination of prior art references that included children's books on making arts-and-crafts types of pumpkins out of paper bags and conventional plastic lawn or trash bags. ${ }^{169}$ The Federal Circuit reversed the Board, holding that, though each element of the pumpkin bag invention was contained in the prior art, the Board had not identified specific information that suggested combining the references. ${ }^{170}$

In addition to requiring a suggestion, teaching, or motivation to combine references, there also must be a reasonable expectation that the combination will achieve the desired effect in order to establish that the combination invention was obvious. ${ }^{171} \mathrm{~A}$ suggestion to combine, absent a reasonable expectation of success, simply renders the combination "obvious to try," an outcome not sufficient to establish obviousness. ${ }^{172}$ An "invention is 'obvious to try' 'where the prior art [gives] either no indication of which parameters [are] critical or no direction[s] as to which of many possible choices is likely

166 In re Dembiczak, 175 F.3d 994, 999 (Fed. Cir. 1999). Whether there was motivation to combine is a question of fact. Id. at 1000 .

167 Id. at 999.

168 Id. at 996.

169 Id. at $997-98$.

170 Id. at 1000 . Similarly, the Federal Circuit reversed a PTO rejection of an application for a patent on a television remote control that utilized two known features because the PTO had not identified specific reference evidence of a motivation to combine; the PTO instead had simply relied on the "common sense" of a PHOSITA. In re Lee, 277 F.3d 1338, 1345 (Fed. Cir. 2002).

171 In re Merck \& Co., 800 F.2d 1091, 1097 (Fed. Cir. 1986).

172 In re Geiger, 815 F.2d 686, 688 (Fed. Cir. 1987); see also Ecolochem, Inc. v. S. Cal. Edison Co., 227 F.3d 1361, 1376-79 (Fed. Cir. 2000) (instructing that while a prior art reference may "seem[] like an obvious place to start ... 'obvious to try' is not the standard”); Gillette Co. v. S.C. Johnson \& Son, Inc., 919 F.2d 720, 725 (Fed Cir. 1990) (explaining that though "a general disclosure may pique the scientist's curiosity, such that further investigation might be done as a result of the disclosure, [where] the disclosure itself does not contain a sufficient teaching of how to obtain the desired result," such a disclosure simply renders the combination obvious to try, but not obvious for purposes of patent validity) (quoting In re Eli Lilly \& Co., 902 F.2d 943, 945 (Fed. Cir. 1990)). 
to be successful." 173 Absolute predictability is not required to render an invention obvious, but there must be guidance and a reasonable expectation of the desired result. ${ }^{174}$

\section{Single Reference Non-Obvious Determinations}

Though less common in reported decisions, an invention may be determined to be obvious in light of a single prior art reference as well as in light of a combination of references. ${ }^{175}$ Here, the issue is whether the differences between the invention and the reference would have been obvious to a PHOSITA. Graham itself concerned such an analysis: whether modifications to a plow hinge were non-obvious in light of individual prior art reference plow hinges. 176

Similarly, in a more recent case, the Federal Circuit held that a pharmaceutical patent was obvious in light of a single reference. ${ }^{177}$ The reference indicated that any of 1,200 combinations of chemical compounds listed would produce the result the patent applicant was attempting to achieve with a new drug. ${ }^{178}$ The court held the invention obvious, reasoning that "the [single reference] would have suggested to one of ordinary skill in

173 Merck \& Co. v. Biocraft Labs., Inc., 874 F.2d 804, 807 (Fed. Cir. 1989) (quoting In re O'Farrell, 853 F.2d 894, 903 (Fed. Cir. 1988)). Similarly, in Merck \& Co. v. Teva Pharmaceuticals USA, Inc., the court held that it was only "obvious to try" various combinations of chemicals disclosed in the prior art, when it was necessary for the patentee to engage in trial and error to find the combination that would achieve the desired effectiveness of the osteoporosis drug at issue. $228 \mathrm{~F}$. Supp. 2d 480, 503 (D. Del. 2002), aff d, Merck \& Co. v. Teva Pharms. USA, Inc., 347 F.3d 1367 (Fed. Cir. 2003).

${ }^{174}$ In re Merck \& Co., 800 F.2d at 1097; see ManUal of Patent EXamining PROCEDURE $\S 2143.02$ (7th ed. 1998) (stating that a reasonable expectation of success is required for a "modification or combination" of prior art references to render an invention obvious; there must have been a reasonable expectation that the modification or combination would be successful).

175 Doctrinally, any analysis that concludes certain references cannot be combined should also consider whether the invention is obvious in light of any of the references standing alone. Most reported decisions appear to ignore this step.

176 Graham v. John Deere Co., 383 U.S. 1, 21-26 (1966). The patent at issue in Graham was evaluated for obviousness in light of two different individual referencesanother Graham patent and the Glencoe patent. The non-obvious analysis was not based on a combination of these references, but considered whether the Graham patent at issue was obvious in light of each reference individually. The Supreme Court held that the Graham patent was obvious in light of Graham's prior patent and that it was independently obvious in light of Glencoe as well. Id.

177 Merck \& Co., 874 F.2d at 807.

178 Id. 
the art that this process [experimenting with the 1,200 combinations] should be carried out and would have a reasonable likelihood of success."179

The Federal Circuit has also held that an invention may be obvious in light of a single reference where a different element is substituted for an element used in the reference. ${ }^{180} \mathrm{An}$ invention is obvious in this circumstance where the substitution is known to a PHOSITA and is known to achieve the desired result. ${ }^{181}$ The Federal Circuit applies the obvious to try and reasonable expectation of success doctrines discussed earlier to nonobvious analyses involving single references as well. ${ }^{182}$

The judiciary, however, has not developed any particular jurisprudential requirements to attempt to avoid the hindsight bias when evaluating whether an invention is non-obvious in light of a single reference.

\section{The Non-Obvious Landscape}

This review of the non-obvious doctrine allows a more precise evaluation of how the hindsight bias is expected to operate. Consider multiple reference non-obvious analyses first. Where evidence of a suggestion, teaching, or motivation to combine references exists, the hindsight bias and case law are expected to operate powerfully to lead to a holding that it was obvious to combine the references, and consequently to a holding that the invention was obvious. As a result, the non-obvious validity standard has effectively been raised, beyond that legislated in the Patent Act, for this category of invention. Some inventions for which a suggestion to combine exists still are non-obvious. ${ }^{183}$ This is particularly true where the suggestion comes from the nature of the problem or knowledge of a person having ordinary skill in the art. Just because a reference suggests a

179 Id. (quoting In re Dow Chem. Co., 837 F.2d 469, 473 (Fed. Cir. 1988)). The court held that the combination at issue was not merely "obvious to try," despite the fact that the combination Merck settled on was not "highlighted as [a] preferred embodiment[]," because the prior art taught that any of the 1200 combinations would achieve the desired result. $I d$. at 809 . Because the prior art gave "direction as to which of many possible choices is likely to be successful," Merck's invention was obvious, as opposed to simply being obvious to try. Id. (quoting In re O'Farrell, 853 F.2d 894, 903 (Fed. Cir. 1988)).

180 Medpointe Healthcare, Inc. v. Hi-Tech Pharmacal Co., 115 F. App'x 76 (Fed. Cir. 2004).

$181 \mathrm{Id}$. at 80.

182 See, e.g., Merck \& Co., 874 F.2d at 809.

183 See Thomas C. Chuang, Obvious Inventions and the Nature of the Problem Being Solved, 17 INTELL. PROP. \& TECH. L.J. 10, 13 (2005) (noting that an invention may be non-obvious even where it solves the same problem as references teaching the individual elements of the invention). 
combination does not necessarily mean that it was obvious for a PHOSITA to make the combination or that it was obvious for a PHOSITA to know how to make the combination. ${ }^{184}$ Due to the combination of patent doctrine and the hindsight bias, however, such a holding may be effectively foreclosed. In this regard, the suggestion rule is expected to be over-inclusive: some inventions that actually are non-obvious will be denied as obvious.

Where a suggestion, teaching, or motivation to combine does not exist, on the other hand, the Federal Circuit has potentially created a situation where holding an invention obvious may be less likely than is appropriate. Simply because combining references is not explicitly suggested in the prior art may not always mean that it was non-obvious to combine the references. ${ }^{185}$ Scientists and engineers, for instance, sometimes may not record obvious aspects of ordinary skill in their field "either because such tacit knowledge is not amenable to verbal description or because practitioners are motivated to publish novel applications ... not routine applications." 186 Or, a recent advance (such as the advent of the Internet)

184 See id. (noting that "there may be technical obstacles that must be solved in order to take individual elements from the prior art and combine them").

185 FED. TRADE COMM'N, supra note 5, ch. 4, at 12-15; NATIONAL RESEARCH CouncIL, supra note 5, at 90; John F. Duffy \& Robert P. Merges, The Story of Graham v. John Deere Company: Patent Law's Evolving Standard of Creativity, in INTELLECTUAL PROPERTY STORIES 109, 154 (Jane C. Ginsburg \& Rochelle Cooper Dreyfuss eds., 2006); Rebecca S. Eisenberg, Obvious to Whom? Evaluating Inventions from the Perspective of PHOSITA, 19 BERKELEY TECH. L.J. 885, 894 (2004); Glynn S. Lunney, Jr., Patent Law, the Federal Circuit, and the Supreme Court: A Quiet Revolution, 11 SUP. CT. ECON. REV. 1, 21 (2004); Jay Dratler, Jr., Does Lord Darcy Yet Live? The Case Against Software and Business-Method Patents, 43 SANTA ClaRA L. REV. 823, 889 (2003); Joshua McGuire, Nonobviousness: Limitations on Evidentiary Support, 18 BERKELEY TECH. L.J. 175, 176 (2003).

Arguably, the Federal Circuit has created what amounts to a "super-anticipation" requirement here. Anticipation is the doctrine under which the novelty validity requirement is evaluated. Brown v. 3M, 265 F.3d 1349, 1351 (Fed. Cir. 2001). Each and every element of claimed subject matter must be found in a single reference in order for that subject matter to be anticipated, and therefore non-novel. Id. For the non-obvious analysis, multiple prior art references may be combined, but only where there is a suggestion, teaching, or motivation to combine them in the prior art. That is, the prior art (now as a whole) must contain each and every element of the claimed invention in order for the invention to be held obvious. Where the knowledge of the PHOSITA or the nature of the problem provides the basis for combining references (i.e., where the suggestion to combine is implicit), however, the "super-anticipation" analogy does not hold well.

186 IP Professors' Amici Brief, supra note 5, at 11; see NATIONAL RESEARCH COUNCIL, supra note 5, at 90 ("[S]cientists, artisans, and creative people generally speaking strive to publish non-obvious information. So if it is obvious to those of skill in the art to combine references, it is unlikely that they will publish such information.") 
may render a variety of new changes obvious (such as one-click shopping), but the precipitating advance may be too new to have been recorded in prior art. On this basis, some commentators argue that the Federal Circuit's suggestion doctrine is expected to be under-inclusive and that it contradicts the statutory dictate of the Patent Act. ${ }^{187}$

The impact of the suggestion test, however, is more complex. A decision-maker may rely on the "nature of the problem to be solved" or "knowledge of persons of ordinary skill in the art" as implicit bases for combining prior art in the non-obvious analysis. ${ }^{188}$ To the extent a decisionmaker relies on these criteria, the potential under-inclusive nature of the suggestion test is mitigated. ${ }^{189}$ Further, the nature of the problem and PHOSITA knowledge criteria are significantly subjective. ${ }^{190}$ Because these standards are open to interpretation, conclusions regarding whether it is appropriate to combine references are likely subject to the hindsight bias in practice. Decision-makers will be excessively prone (due to the hindsight bias) to conclude that the nature of the problem to be solved or knowledge of PHOSITA suggests combining references, resulting in a bias towards finding an invention obvious. The suggestion test thus may be consistent with existing patent law, but still cannot be expected to ameliorate the hindsight bias.

The scenarios used in the present study help elucidate the limits of the suggestion, teaching, or motivation to combine doctrine. The fishing lure scenario is one in which the nature of the problem appears to suggest combining prior art. The inventor is explicitly seeking a salty lure that will not spoil or lose its taste in water. The prior art contains plastic lures that will not spoil and various other lures to which salt has been added, but which spoil or lose their taste. This situation is quite similar to Pro-Mold \& Tool,

(emphasis added); McGuire, supra note 185, at 176 ("[C]ited references are often only a subset of a larger pool of relevant references.").

187 See IP Professors' Amici Brief, supra note 5, at 5-6 (arguing that the Federal Circuit's suggestion requirement contradicts Supreme Court precedent because it is inconsistent with Graham); Eisenberg, supra note 185, at 894 (same); Lunney, supra note 185 , at 21 (same).

188 In re Rouffet, 149 F.3d 1350, 1357 (Fed. Cir. 1998); Ruiz v. A.B. Chance Co., 357 F.3d at 1276 (Fed. Cir. 2004).

189 Christopher A. Cotropia, Patent Law Viewed Through an Evidentiary Lens: The "Suggestion Test" as a Rule of Evidence in Patent Law, 2006 BYU L. REV. (forthcoming 2006). Some commentators contend that the courts actually tend to ignore suggestions from the nature of the problem to be solved or the knowledge of a PHOSITA. See, e.g., FED. TRADE COMM'N, supra note 5, ch. 4, at 12 (quoting Professor John Duffy for stating that the feel of the case law is that the courts only recognize teachings from the prior art).

190 See, e.g., Ruiz, 357 F.3d at 1276 (holding that the suggestion to combine references may be found implicitly in the nature of the problem to be solved). 
the baseball trading card case discussed above. Under current precedent, because the nature of the problem suggests the combination, the invention almost undoubtedly would be held obvious (as was the result in Pro-Mold \& Tool). Seventy-seven percent of respondents in the foresight condition (who were not restricted by the prior art combination rules or impacted by the hindsight bias), however, believed that the lure invention was non-obvious.

The baseball pitch scenario presents a situation in which it is unclear whether there is a suggestion, teaching, or motivation to combine the prior art references. The elements of the solution are each contained in the prior art, but there is no explicit suggestion to combine them. The knowledge of a PHOSITA, however, arguably provides a motivation to combine the references. Seventy-six percent of respondents in the foresight condition (again, who were not restricted by the prior art combination rules or impacted by the hindsight bias), however, believed that the baseball invention was non-obvious. The present study thus indicates that, as hypothesized, the suggestion test does not resolve the hindsight bias.

Admittedly, perhaps the fishing lure combination was not suggested by the nature of the problem, and perhaps the baseball combination was not within the knowledge of persons having ordinary skill in the art. But this recognition simply underscores the subjective nature of the Federal Circuit's combination standard. ${ }^{191}$ It also reveals that combination precedent, as it has evolved, is caught in a Catch- 22 concerning doctrinal accuracy. If the doctrine provides a bright-line rule, it yields over-inclusive and underinclusive non-obvious results; if the doctrine provides a subjective standard, it yields non-obvious determinations still subject to the hindsight bias. ${ }^{192}$ Either way, current non-obvious decisions are incoherent.

Completing the non-obvious landscape, the final category concerns single reference non-obvious analyses. Simply put, there is little guidance for decision-makers on how to avoid the hindsight bias in these instances. The hindsight bias likely operates to significantly affect this type of non-obvious determination. In addition, the dearth of single reference non-obvious analyses in the case law suggests something is operating to lead courts away

191 See Chuang, supra note 183, at 13 (noting that "the problem being solved ... can be characterized narrowly or broadly depending on whether it is desired to limit or expand the scope of prior art references relevant under the test").

192 It is unclear in the abstract which problem is worse: is it worse to grant a patent on an obvious (and therefore undeserving) invention, subjecting society to unnecessary monopoly costs and potentially retarding further progress because of the exclusionary rights in the invention; or is it worse to deny a patent on a non-obvious (and otherwise deserving) invention, thereby denying an inventor his or her deserved monopoly and providing less of an incentive to invent and innovate than is believed to be optimal under the Patent Act? 
from such consideration. ${ }^{193}$ Perhaps the strong focus on the suggestion test and the relative paucity of Federal Circuit guidance on single reference analysis creates a bias against conducting it, an additional problem for current doctrine.

Intriguingly, under current case law, how an invention is characterized could determine whether it is held non-obvious, though such characterization actually is not relevant to the degree of ingenuity or creativity that went into the invention. For astute inventors, existing case law should lead to strategic behavior before the PTO and the courts concerning whether an invention is characterized as a combination invention or as an advance over single prior art. How to characterize one's invention, however, is not susceptible to easy strategy. Like Ulysses facing Scylla and Charybdis, inventors have to choose between characterizing their invention as an advance over a single reference (and be subject to the hindsight bias) and characterizing their invention as a combination invention (and be subject to the decision-maker finding a suggestion to combine in the prior art). Where the inventor believes a decision-maker will not be able to identify a suggestion to combine in the prior art, it will be better to try to characterize the invention as a combination invention. Where the inventor believes the decision-maker will find such a suggestion, he or she will want to characterize the invention as an advance over single prior art.

The study results strongly support the judiciary's efforts to combat the non-obvious hindsight problem, but indicate that the Federal Circuit's suggestion test does not provide a complete solution. The Supreme Court will try its hand at solving the hindsight conundrum next-it has granted certiorari to consider the suggestion, teaching, or motivation test in the upcoming term. ${ }^{194}$

193 Fulton, the hexagonal shoe sole case, provides an example. The court did not discuss whether Fulton's invention could have been found obvious in light of Bowerman alone, which contained "all of the limitations in the claim except for those relating to the hexagonal shaped projected surfaces." In re Fulton, 391 F.3d 1195, 1199 (Fed. Cir. 2004). In light of the fact that the Bowerman reference discloses the use of "cylindrical polygon shaped studs or projections" generally, $i d$., and that the court recognizes that one skilled in the art would know that a hexagon was such a shape, it appears that Fulton's invention is obvious in light of Bowerman alone. The court, however, only conducts a combination invention non-obvious analysis, in combination with Pope. Id. at 1200-01.

194 Teleflex, Inc. v. KSR Int'l Co. 119 F. App'x 282 (Fed. Cir. 2005), cert. granted, 74 U.S.L.W. 3720 (U.S. June 26, 2006) (No. 04-1350). The follow-up study on the effects of the suggestion test on the hindsight bias indicates that the suggestion test does not lower the non-obvious standard in the manner claimed by its critics, but also, as hypothesized here, that the test does not resolve the hindsight bias. Mandel, supra note 143. 


\section{The Presumption of Validity}

Although not intended as such, one could argue that the presumption of validity which adheres to patents granted by the $\mathrm{PTO}^{195}$ may mitigate the hindsight bias. The Federal Circuit has interpreted this presumption to require that invalidity be established by clear and convincing evidence. ${ }^{196}$ The argument here would be that this procedural presumption provides a countervailing influence to the substantive hindsight bias. ${ }^{197}$ As a threshold matter, the presumption is not intended to serve this purpose. This line of argument is problematic as a remedy to the hindsight problem for other reasons as well.

First, the extent to which this burden of proof balances the hindsight bias is unknown. ${ }^{198}$ Some empirical evidence indicates that the standard of proof does not influence the outcome of cases, signifying that the presumption of validity may offer no countervailing tendency at all. ${ }^{199}$ Second, there is little reason to believe that the magnitude of any effect produced by the presumption of validity matches that of the hindsight bias - even if it has some impact, the presumption of validity may undercompensate or overcompensate for the bias. Third, to the extent the presumption of validity is supposed to provide a presumption, it no longer serves this role-it would simply compensate for the hindsight bias, not provide the statutorily indicated presumption. Fourth, it is extremely unlikely that the inventions for which the presumption of validity may affect non-obvious decisions are the same as those inventions that appear obvious only in hindsight. Stated another way, under current jurisprudence, some group of actually nonobvious inventions will be invalidated due to the hindsight bias. Another group of inventions would be invalidated in litigation but for the

19535 U.S.C. $\S 282$ (Supp. 2002).

196 Al-Site Corp. v. VSI Int'l, Inc., 174 F.3d 1308, 1323 (Fed. Cir. 1999). This interpretation has been criticized by some as unwarranted. FED. TRADE COMM'N, supra note 5 , ch. 5 , at 26-28.

197 See Christine Jolls et al., A Behavioral Approach to Law and Economics, 50 STAN. L. REV. 1471, 1529-30 (1998) (identifying raising the evidentiary standard as a possible means to compensate for the hindsight bias in tort litigation).

198 See Richard A. Posner, Rational Choice, Behavioral Economics, and the Law, 50 STAN. L. REV. 1551, 1572 (1998) (criticizing Jolls, Sunstein, and Thaler for proposing modified standards of proof on limited evidence).

199 Dorothy K. Kagehiro \& W. Clark Stanton, Legal vs. Quantified Definitions of Standards of Proof, 9 LAW \& HUM. BEHAV. 159, 163-73 (1985) (discussing an empirical study finding that different standards of proof produced similar jury verdicts); compare Kevin M. Clermont, Procedure's Magical Number Three: Psychological Bases for Standards of Decision, 72 CORNELL L. REV. 1115, 1148 (1987) (arguing that each common standard of proof has a distinct psychological meaning). 
presumption of validity. There is no reason to expect a one-to-one correspondence between these groups. At questionable best, the presumption of validity may result in the proper total number of inventions being held valid, but not in the proper individual inventions being held valid. ${ }^{200}$ Such a result raises due process concerns. Lastly, the presumption of validity does not apply to threshold patenting decisions at the PTO. Hindsight bias will operate to deny patents on actually deserving inventions, and such inventions will never get the benefit of the presumption.

Existing jurisprudence thus substantially fails to mitigate the effects of the hindsight bias. This failure is particularly problematic considering the results of the current study, which indicate that the hindsight bias in patent law is more severe and persistent than expected. Patent hindsight problems, however, are even more pervasive than so far discussed-they are not limited to non-obvious decisions. Though previously unrecognized, several other patent doctrines are subject to hindsight problems as well.

\section{HiNDSIGHT Bias Throughout PaTENT LAW}

A curious aspect of extant patent jurisprudence is that it recognizes hindsight bias concerns for non-obvious determinations and has developed elaborate precedent in an attempt to handle these concerns, but has failed to realize that there are similarly critical concerns that the hindsight bias raises for other patent law determinations. The following sections analyze how the hindsight bias renders decisions in the areas of the doctrine of equivalents, claim construction, the on-sale bar, and enablement problematic.

\section{A. Doctrine of Equivalents}

Patent infringement occurs when someone makes, uses, or sells a patented product or process without permission of the patent owner. ${ }^{201}$ "Literal" infringement occurs where the accused device is literally covered by the patent claims-the patent claims actually describe the infringing product or process. ${ }^{202}$

Even if an accused device does not fall within the literal claims of a patent, it still may infringe under the "doctrine of equivalents," which

200 Despite its other deficiencies, this result theoretically could produce efficient incentives to invent or innovate. If the presumption of validity results in the proper number of patents being granted, and inventors do not know ex ante that their patent applications are more or less likely than the average application to be affected by the presumption or the hindsight bias, inventors may face efficient incentives.

20135 U.S.C. $\$ 271$ (a) (Supp. 2003).

202 Graver Tank \& Mfg. Co. v. Linde Air Prods. Co., 339 U.S. 605, 607 (1950). 
provides for patent infringement where every element of an accused device is contained either literally or by its equivalent in the claims of a patent. ${ }^{203}$ The basis for the doctrine of equivalents is evident-one should not be able to evade infringement simply by making an insubstantial change to an element of a patent.

Application of the doctrine of equivalents is subject to "prosecution history estoppel," which prevents a patent owner from using the doctrine of equivalents to cover subject matter which the patent owner disclaimed before the PTO in order to acquire the patent in the first instance. ${ }^{204}$ If, for instance, a patent owner narrowed claims during patent prosecution to avoid prior art that would render the patent obvious, the patent owner cannot use the doctrine of equivalents to cover an accused device that contains the elements disclaimed during prosecution. ${ }^{205}$

Prosecution history estoppel itself has doctrinal restrictions. It does not create a complete prohibition on a finding of equivalence for all elements surrendered by narrowing amendments made during prosecution. ${ }^{206}$ Though the narrowing of an amendment demonstrates what a claim is not (it does not cover the specific prior art avoided), the narrowed amendment still may fail to capture precisely what a claim is. ${ }^{207}$ In particular, the claim element may inappropriately have been narrowed too far. In this case, the doctrine of equivalents may still be available to recapture that portion of the subject matter that did not need to be disclaimed in order to receive a patent. ${ }^{208}$

The Supreme Court has identified three specific circumstances where a claim may have been mistakenly narrowed too far and therefore where prosecution history estoppel does not bar a finding of equivalents. These circumstances are (1) where the equivalent was unforeseeable at the time of the application, (2) where the rationale underlying the amendment bore no more than a tangential relation to the equivalent in question, or (3) where there is some other reason that the patentee could not reasonably have been expected to have described the equivalent in question. ${ }^{209}$

Determining whether an equivalent was unforeseeable at the time of patent application raises the specter of the hindsight bias. Because such analyses will only apply where the equivalent was not available at the time

203 Warner-Jenkinson Co. v. Hilton Davis Chem. Co., 520 U.S. 17, 29 (1997).

204 Festo Corp. v. Shoketsu Kinzoku Kogyo Kabushiki Co., 535 U.S. 722, 736 (2002); Warner-Jenkinson, 520 U.S. at 30.

205 Festo, 535 U.S. at 736.

206 Id. at $737-38$.

207 Id. at 738.

$208 \mathrm{Id}$.

209 Id. at $740-41$. 
of patent application but has subsequently been developed, the hindsight bias will operate to make the equivalent not only appear to have been more likely at the time of application, but also appear to have been relatively foreseeable. ${ }^{210}$ Decision-makers will routinely judge equivalents to have been more foreseeable than they actually were, precluding application of the doctrine of equivalents in appropriate situations.

The tangential relation and unable to describe analyses also will likely be subject to hindsight bias. Once the equivalent is known in hindsight, there will be a tendency to conclude that a patent drafter should have recognized it in foresight, and therefore should have drafted the patent claims to cover it. 211 Patent owners consequently receive a smaller scope of patent protection than they are entitled to receive.

The hindsight effect may influence application of the doctrine of equivalents in other ways. Hindsight will tend to make substitutes that accused infringers incorporate appear to be more obvious variations than they actually were. It is possible that a decision-maker would be more likely to find an obvious-appearing substitute equivalent in hindsight than he or she would be to find the same substitute equivalent in foresight (where it would appear less obvious). ${ }^{212}$ It is possible, in this manner, that the hindsight bias increases the general scope of the doctrine of equivalents.

\section{B. Claim Construction}

Claim construction concerns determining what the claims of a patent mean, and therefore what subject matter they cover. Often claim construction is the decisive issue in infringement litigation-one interpretation may render an accused device infringing, while another would not.

Claim construction is based on the language of the claims, the patent specification, the prosecution history, and potentially extrinsic evidence, such as expert testimony concerning how those skilled in the art would have interpreted the claims. ${ }^{213}$ Because claim construction is based on determining the meaning of the claims to a person having ordinary skill in

210 See supra Parts II.B, III; Douglas Lichtman, Substitutes for the Doctrine of Equivalents: A Response to Meurer and Nard, 93 GEO. L.J. 2013 (2006) (noting that courts may overestimate the ability of patent drafters to foresee the effects of claims language due to the hindsight bias).

211 Supra, note 210 , at 2025.

212 I am grateful to Mark Lemley for identifying this potential effect.

213 Markman v. Westview Instruments, Inc., 52 F.3d 967, 980-81 (Fed. Cir. 1995), aff'd, 517 U.S. 370 (1996); Ferguson Beauregard v. Mega Sys., L.L.C., 350 F.3d 1327, 1338 (Fed. Cir. 2003). 
the art at the time the patent application was filed,214 it requires a hindsight determination. As such, the hindsight bias is expected to impact claim construction analyses. ${ }^{215}$ Courts have offered little guidance on how a decision-maker is supposed to determine how a claim would have been interpreted in the past, ${ }^{216}$ let alone how to avoid hindsight bias in this interpretation. The hindsight bias will cause a decision-maker to ignore the extent to which the meaning of claim terms has changed over time.

Perhaps further aggravating the hindsight bias in claim construction, the use of extrinsic evidence in claim interpretation is somewhat disfavored. ${ }^{217}$ Extrinsic evidence may only be used when a term is ambiguous. ${ }^{218}$ It is precisely extrinsic evidence, however, that may reveal that term meanings have changed over time and how they have changed. Limiting claim construction to intrinsic evidence in certain cases may blind the decisionmaker to the fact that a term's meaning has changed. ${ }^{219}$

\section{On-Sale Bar}

One element of the novelty validity requirement is the "on-sale" bar. A patent will not issue on an invention that was on-sale in the United States more than one year prior to the application filing date. ${ }^{220}$ The Supreme Court has held that an invention is on-sale when the invention (1) is the subject of

214 Phillips v. AWH, Corp., 415 F.3d 1303 (Fed. Cir. 2005).

215 See supra Part III; Dan L. Burk \& Mark A. Lemley, Is Patent Law TechnologySpecific?, 17 BERKELEY TECH. L.J. 1155, 1199 (2002) (noting that "hindsight bias risks infecting the PHOSITA analysis in ... claim scope").

216 Donald S. Chisum, ChISUM ON PATENTS $\$ 18.03(2)(\mathrm{g})(2005)$ ("The time framework for construing patent claims is the subject of surprisingly sparse judicial authority.").

217 See Phillips, 415 F.3d at 1315, 1319.

218 Id. at 1324 (stating that extrinsic evidence may only be used so "long as [it is] not used to contradict claim meaning that is unambiguous in light of the intrinsic evidence").

219 See Tex. Digital Sys., Inc. v. Telegenix, Inc., 308 F.3d 1193, 1203-04 (Fed. Cir. 2002) (stating that application-contemporary dictionaries, treatises, and encyclopedias should be consulted as the first step of claim construction, before consulting intrinsic evidence, to provide an objective definition of claim terms). Texas Digital Systems was criticized in Phillips for placing too much reliance on extrinsic evidence. Phillips, 415 F.3d at 1303. Just because extrinsic evidence may provide the best means of identifying how claim terms have changed over time, and of ameliorating the hindsight bias in claim construction, does not mean that use of extrinsic evidence does not also raise other concerns, such as reliability. See Mark A. Lemley, The Changing Meaning of Patent Claim Terms, 104 Mich. L. REV. 101 (2005).

22035 U.S.C. $\S 102$ (Supp. 2002). 
a commercial offer for sale, and (2) is ready for patenting. ${ }^{221}$ "Ready for patenting" may be satisfied either by reduction to practice or by the "prepar[ation of] drawings or other descriptions of the invention that were sufficiently specific to enable a person skilled in the art to practice the invention."222

Requiring a judgment concerning what a person having ordinary skill in the art would have understood at a time in the past necessitates a hindsight determination, and therefore is anticipated to lead to a hindsight bias. Decision-makers will be more likely to conclude that an invention was ready for patenting than it actually was, and consequently more likely to conclude that an invention was on-sale than is doctrinally appropriate.

\section{Enablement}

A core element of the adequate disclosure patent validity requirement is that the patent application disclose enough information such that a person of ordinary skill in the art could make and use the invention. ${ }^{223}$ This requirement is referred to as enablement.

The enablement requirement raises hindsight bias concerns along two related fronts. First, the level of skill of a PHOSITA will have changed between the time a patent application was filed and litigation. Second, how to make and use the invention may have become clearer as a result of time, familiarity, or technological advance. Due to the hindsight bias, each of these factors is expected to cause decision-makers to perceive that patent disclosures were more enabling than they actually were, consequently leading to inappropriate enablement conclusions. ${ }^{224}$

The impact of the hindsight bias will be greatest for technologies that are advancing the fastest. The greater the difference between the state of the art (and PHOSITA skill level) at the time of invention versus at the time obviousness is determined, the greater the influence of the bias. As technological progress is often fastest in the early stages of new technology development, the hindsight bias may be particularly influential in causing broad, early-stage patents to be improperly held to have been enabling. This effect is particularly troubling as it is exactly these types of patents that may

221 Pfaff v. Wells Elec., Inc., 525 U.S. 55, 67 (1998).

222 Id. at 67-68.

22335 U.S.C. $\$ 112(2000)$.

224 Burk \& Lemley, supra note 215, at 1199 (noting that "hindsight bias risks infecting the PHOSITA analysis in enablement"). 
cause the greatest limitations and inefficiencies for future technological advancements. ${ }^{225}$

\section{E. Hindsight Bias in Patent Law}

The hindsight effect thus operates to distort decisions throughout patent law. Many hindsight bias effects are detrimental to the patent owner. Inventions will appear more obvious and ready for patenting than they actually were, increasing the probability that a patent will be held invalid. Valid patents will be excessively limited in scope because equivalent elements will appear more foreseeable than they actually were, erroneously limiting application of the doctrine of equivalents. Conversely, other hindsight effects will favor the patent owner. Most significantly, the hindsight bias will favor the inventor in enablement disputes, particularly for rapidly advancing technologies, as it will make a patent appear more enabling than it actually was. Hindsight may also operate to make nonequivalent substitute elements appear equivalent and to make secondary consideration evidence appear more indicative of non-obviousness than it actually is. Whether the effect of hindsight bias on claim construction benefits or harms the patent holder will vary from case to case.

Not all hindsight effects are equally problematic. Whether an invention was ready for patenting so as to raise an on-sale bar is only occasionally at issue as a practical matter. Application of the doctrine of equivalents, enablement concerns, and claim construction issues are routinely raised in patent litigation, though the hindsight bias will only be relevant in the latter two cases where the state of the art has changed between the time of application and litigation. The non-obvious hindsight problem, unlike the other doctrines, implicates every single patent —each must be evaluated for obviousness, and in each instance the examiner is aware of the invention. Exacerbating this impact, as discussed, obviousness is the most commonly litigated patent validity issue.

In sum, the hindsight bias pervades patent law to an extent and magnitude not previously identified. Though the bias can be either detrimental or beneficial to the patent owner depending on the invention and issue involved, hindsight effects cannot be considered to balance out. The binary nature of patent validity decisions and the incongruence of different hindsight effects results in each hindsight impact presenting an independent, inappropriate influence on patent validity and infringement decisions. A patent perceived to be more enabling than it actually was is useless to an

225 See Robert P. Merges \& Richard R. Nelson, On the Complex Economics of Patent Scope, 90 CoLUM. L. REV. 839 (1990) (arguing that broad, early patents can reduce future technological advance). 
inventor whose entire patent is (improperly) denied as obvious. Conversely, a patent that survives the non-obvious hurdle despite the hindsight bias can still create substantial inefficiency and inequity if it is held to cover (enable) a greater scope of subject matter than is appropriate. Determining how to cleanse patent law of hindsight bias therefore is critical.

\section{Solving THE NoN-ObVious HINDSight BIAS DilemMA}

The legal system's failure to ameliorate the effects of the hindsight bias is not entirely surprising. The hindsight bias has proven remarkably difficult to diminish, let alone eliminate, in judgment. Diverse efforts in a wide variety of fields have failed to systematically or completely eliminate this bias.

\section{A. Debiasing}

Alerting people to the hindsight bias and its dangers, and exhorting them to try to avoid it, has little effect in reducing the bias.226 This result was confirmed in the present study. Mock jurors in the debiasing condition were instructed about the hindsight problem and told to try to avoid using hindsight in their judgment. The debiasing instructions did not significantly reduce the hindsight bias.

Similar results were found in the flood precaution tort study discussed earlier. In a debiasing condition, hindsight mock jurors were instructed by the judge concerning the influential effects of hindsight and told to consider alternative outcomes. ${ }^{227}$ The study found no significant difference in the extent of hindsight bias between participants in the hindsight condition and those in the debiasing condition. ${ }^{228}$ A separate tort study in the commercial litigation context, however, did find significant debiasing under certain circumstances. ${ }^{229}$ The debiasing effort there came from the closing argument of the defense attorney, who sought to minimize the effect of the bias by instructing jurors to focus on the pre-outcome timeframe and particularly by (1) telling the mock jurors that the plaintiff's strategy was to have the jurors be "Monday morning quarterbacks," and (2) that the jurors should avoid

226 Kamin \& Rachlinski, supra note 2, at 92; Gordon Wood, The Knew-It-All-Along Effect, 4 J. ExPerimental PSychol.: Hum. Perception \& PerformanCe 345 (1978); Baruch Fischhoff, Perceived Informativeness of Facts, 3 J. EXPERIMENTAL PSYCHOL.: HuM. PERCEPTION \& PERFORMANCE 349 (1977).

227 Kamin \& Rachlinski, supra note 2, at 93.

228 Id. at 98 .

229 Stallard \& Worthington, supra note 2. 
using hindsight in judging the defendants. ${ }^{230}$ The study found that the defense attorney's instructions significantly reduced (but did not eliminate) the hindsight bias. ${ }^{231}$ This method is worthy of further investigation, but the results have not been replicated, and, as discussed, many very similar efforts have not been successful. ${ }^{232}$

Other debiasing attempts have been unsuccessful as well. Providing greater education about the topic being judged does not reduce the hindsight bias. ${ }^{233}$ This indicates that trying to reduce the bias in patent cases through expert testimony or judicial instruction concerning the state of the art likely will not be productive. Instructing hindsight decision-makers to consider how other alternatives might be correct has had some positive effect in certain studies, ${ }^{234}$ but does not appear practical in the patent context. Further, the flood precaution tort study found no effect on the hindsight bias from debiasing attempts along these lines. ${ }^{235}$

Similarly, increased motivation or incentives do not ameliorate the hindsight bias. ${ }^{236}$ Suggesting to people that they try harder, ${ }^{237}$ increasing the personal relevance of the task, ${ }^{238}$ and rewarding people for unbiased responses ${ }^{239}$ all have failed to improve the accuracy of hindsight judgment. Even after being told of the bias, individuals are unaware that it is impacting

230 Id. at 675 .

231 Id. at 679 . Twenty-nine percent of foresight participants thought that the defendants were negligent, $57 \%$ of participants in the hindsight condition thought the defendants were negligent, and $37 \%$ of participants in the debiasing condition thought the defendants were negligent. Id.

232 See supra note 226; infra note 240; supra Part III.B.

233 See, e.g., Baruch Fischhoff, Debiasing, in JUDGMENT UNDER UNCERTAINTY: HEURISTICS AND BIASES 422, 430 (Kahneman et al. eds., 1982).

234 See Hal R. Arkes et al., Eliminating the Hindsight Bias, 73 J. APP. PsyCHOL. 305 (1988) (neuropsychologists in hindsight debiasing condition instructed to identify reasons why various possible diagnoses might be correct demonstrated lower hindsight bias than neuropsychologists in non-debiasing hindsight condition).

235 Kamin \& Rachlinski, supra note 2, at 99 . The tort study, however, did not require participants to actually state reasons why other outcomes may have occurred or to list supporting facts for various potential outcomes, requirements that partially successful debiasing studies had included. Id. at 100.

236 Guthrie et al., supra note 4, at 819-20.

${ }^{237}$ M.F. Davies, Reduction in the Hindsight Bias by Restoration of Foresight Perspective: Effectiveness of Foresight Encoding and Hindsight-Retrieval Strategies, 2 Organizational Behav. \& Hum. DeCision MaKING 205 (1987).

${ }^{238}$ T. Connolly \& E.W. Bukszar, Hindsight Bias: Self Flattery or Cognitive Error, 40 J. BEHAV. DECISION MAKING 50 (1990).

${ }^{239}$ W. Hell et al., Hindsight Bias: An Interaction of Automatic and Motivational Factors?, 16 MEMORY \& COGNITION 533 (1988). 
their decision making. Once an outcome is known, individuals are cognitively incapable of properly discounting it. "[T]he hindsight bias [is] essentially impossible to avoid . . correcting for the bias is not feasible."240

Analysis of the conditions necessary for effective debiasing strongly indicates that it cannot be achieved through jury instruction. ${ }^{241}$ Likewise, following certain scholars' recommendations of eliminating juries (and leaving patent decisions to judges) ${ }^{242}$ will not solve the hindsight problem. ${ }^{243}$ Cleansing non-obvious decisions of hindsight bias requires more comprehensive change in patent doctrine and litigation. The revisions proposed here focus on two goals: mitigating the inculcation of hindsight analysis created by case law and modifying litigation so as to remove the opportunity for hindsight bias at trial. ${ }^{244}$

240 Guthrie et al., supra note 4, at 824-25.

241 Two researchers have provided a catalog of conditions necessary for effective debiasing: (1) the individual making the judgment is aware of the bias; (2) the individual knows the magnitude and direction of the bias; (3) the individual is motivated to correct the bias; and (4) the individual has means to correct the bias. Timothy D. Wilson \& Nancy Brekke, Mental Contamination and Mental Correction: Unwanted Influences on Judgments and Evaluations, 116 PsYCHOL. BuLL. 117 (1994). Jury instructions would have a hard time meeting all but the first requirement. SUNSTEIN, supra note 31, at 108; see also Rachlinski, supra note 27, at 603 ("Judicial instructions are unlikely to include a mechanism that would [avoid the hindsight bias].").

242 See, e.g., JAFFE \& LERNER, supra note 6, at 196-97 (arguing for elimination of juries for patent validity decisions).

243 Supra Part III.C. 2 .

244 One author has argued that it would be unwise to attempt to ameliorate the hindsight bias in tort cases without further evidence because a number of other biases favor defendants in the tort context. Philip G. Peters, Jr., Hindsight Bias and Tort Liability: Avoiding Premature Conclusions, 31 ARIZ. ST. L.J. 1277, 1292. None of the biases that Peters identifies (e.g., juror distrust of personal injury plaintiffs, other cognitive biases that favor defendants, and the difficulty for plaintiffs in bringing suit) are applicable countervailing biases in the patent context. The primary additional bias that may apply in patent cases is the status quo bias-a bias in favor of maintaining the status quo. See Daniel Kahneman et al., The Endowment Effect, Loss Aversion, and Status Quo Bias, in ChoICES, VALuES, AND Frames (Daniel Kahneman \& Amos Tversky eds. 2000) (discussing the status quo bias). The status quo bias may lead decision-makers away from a finding of invalidity, but also may lead them towards a finding of no infringement, rendering the status quo bias not advantageous to either party in patent litigation. 


\section{B. Debiasing Patent Law and Litigation}

Doctrinal non-obvious hindsight bias problems may originate with the seminal Supreme Court non-obvious decision in Graham. ${ }^{245}$ Graham requires the decision-maker to focus on the differences between the prior art and the invention. The deconstruction of the invention into discrete elements and repeated focus of the analysis on the invention itself imbues the nonobvious determination with hindsight analysis. Ironically, of course, the Graham Court was concerned about the hindsight bias, and Graham is considered part of a solution to the hindsight problem. ${ }^{246}$ Focusing on the prior art and problem to be solved, rather than concentrating on the invention, could reduce the hindsight bias. ${ }^{247}$ Placing attention on the prior art and problem to be solved would place the decision-maker in a more analogous context to the inventor prior to invention.

Though such a change may reduce the bias in current practice, it cannot be expected to eliminate the hindsight problem - hindsight knowledge would still infect non-obvious decisions. Mitigating the hindsight bias will require significantly reworking patent litigation.

In order to ameliorate the hindsight bias, a patent trial should operate to the maximum extent as if the invention does not exist. This solution cannot be implemented where the trial is heard by a judge, ${ }^{248}$ but can be applied in jury trials, which represent over seventy percent of patent trials. ${ }^{249}$

245 Graham v. John Deere Co., 383 U.S. 1, 36 (1966).

246 John v. Hardy, 727 F.2d 1524, 1529 (Fed. Cir. 1984) (overturning the district court when "[Graham's] guidance was not applied, resulting in the application of hindsight and speculation").

247 Focus on the problem to be solved is somewhat akin to the comparable European patent approach. European patents require an "inventive step," rather than our "nonobvious" requirement, but the standards are quite similar. European Patent Convention, Art. 52(1), http://www.european-patentoffice.org/legal/epc/pdf/epc_2006_v5_bm_en.pdf (last visited November 12, 2006); see European Patent Convention, Art. 56, supra (defining an invention to have "an inventive step if, having regard to the state of the art, it is not obvious to a person skilled in the art"). The inventive step analysis is conducted by identifying the problem to be solved, closest prior art, and whether a person skilled in the art would have claimed the technical features claimed in the invention. European Patent Convention, Rule 27(1)(c); Case Law of the Boards of Appeal of the European Patent Office 101-02 (4th ed. 2001).

248 For a proposal concerning how to bifurcate the non-obvious issue at the PTO, see Mandel, supra note 143.

249 JAFFE \& LERNER, supra note 6, at 123. 
Under this proposal, the issues for trial would be bifurcated. 250 The nonobvious issue often would be tried first, at least for trials in which the same jury is expected to hear all issues. Pre-trial hearings, out of the jury's presence, would determine the analogous, relevant prior art. ${ }^{251}$ Such hearings would determine the admissibility of any expert testimony concerning the level of ordinary skill in the art and what a PHOSITA would know how to do. The pre-trial hearings would also be used to identify what problem the inventor was working on or what problem the invention solved.

Once the evidence probative of the non-obviousness issue is determined, the non-obvious stage of the trial would commence. The parties and their experts would be prohibited from mentioning or identifying the invention during trial. They could only present evidence of the prior art, the skill level and knowledge of a person having ordinary skill in the art, and the problem the inventor was working on. Following trial, the jury would deliberate on whether the advances sought were obvious to a person having an ordinary level of skill in the art.

Possible hindsight bias could further be reduced by structuring jury deliberation through dividing the analysis into a number of subparts with special verdict forms. For instance, the jury should identify what problem the inventor was working on, what the prior art was, and what the ordinary level of skill in the art was. Then the jury can consider a threshold non-obvious question: "In light of the existing prior art, was a solution to the problem obvious to a person having ordinary skill in the art?" If the jury concludes that a solution was not obvious, then the non-obvious validity requirement has been satisfied. The inventor's specific solution cannot be obvious if no solution was obvious.

If the jury concludes that a solution was obvious, a second non-obvious question must be put to the jury. Simply because the jury concluded $a$ solution to the problem was obvious does not mean that the inventor's particular solution was obvious. Where the jury concludes that some solution was obvious, it would be informed of the invention, and then

250 See Jolls, supra note 197 , at 1527-28 (identifying the need to recreate ex ante judgments in order to ameliorate the hindsight bias, and noting the potential for bifurcating negligence cases into liability and damages in this regard). There is no reported patent decision bifurcating the non-obvious issue. Courts have bifurcated patent validity generally from other issues, such as infringement and damages. See, e.g., Novopharm Ltd. v. TorPharm, Inc., 181 F.R.D. 308, 311-12, 1998 U.S. Dist. LEXIS 9602 , at $* 6, * 9$ (E.D.N.C. May 26, 1998) (bifurcating validity and infringement from damages and willfulness); C.R. Bard, Inc. v. M3 Sys., 1994 U.S. Dist. LEXIS 9303 at *3 (N.D. Ill. July 11, 1994) (bifurcating validity from infringement).

251 Not all prior art is considered in the non-obvious determination, only analogous prior art. In re Clay, 966 F.2d 656, 658 (Fed. Cir. 1992). Analogous art comprises those references that a PHOSITA is presumed to have available. Id. 
deliberate over whether the invention was obvious. In addition, a second special verdict form could be given to the jury with detailed instructions for deciding the non-obvious issue. The form would direct the jury to consider reasons that the invention might not have been achieved or was not obvious, and would instruct the jurors to write out these alternatives. Similar requirements have reduced the hindsight bias in other contexts. ${ }^{252}$ Though informing the jury of the invention may introduce some bias, the efforts made up to this point should ameliorate it to the greatest extent possible, and it is impossible to evaluate a specific invention without informing the jury of it. This reworking of a patent trial would go a long way towards ameliorating the hindsight bias and would produce substantially less biased decisions than current jurisprudence. It also identifies a new benefit of jury trials-juries can be shielded from invention knowledge while judges cannot.

This proposal has some limitations. It will only work for inventions of which a jury is not already aware. ${ }^{253}$ Where jurors independently know that the invention has been achieved, the hindsight bias can be expected to operate, even if the proposed trial format is followed. Fortuitously, almost all litigated patents concern inventions that jurors would not be expected to know about. Review of the eighteen-month compilation of non-obvious patent decisions revealed that, conservatively, no more than one in ten concerned an invention that even a well-informed juror might be expected to know about. ${ }^{254}$ Even in rare instances where jurors know or have some idea of an invention, the hindsight bias under the proposal can be no worse than it is currently. ${ }^{255}$

More problematic, perhaps, is that in certain trials the jury might be primed (either unavoidably or intentionally by an accused infringer) about what the invention is. The judge will have to monitor the trial closely to prevent intentional disclosure. Even where intentional disclosure is avoided, the highlighting of certain prior art, problems to be solved, and areas of knowledge of the person having ordinary skill in the art may focus the

252 See supra Part VI.A.

253 See Jolls et al., supra note 197, at 1528-29 (noting that bifurcation of negligence cases to ameliorate the hindsight bias will not work where occurrence of the accident is made apparent in the ex ante condition).

254 This analysis was based on a review of the decisions for inventions that I or my research assistants thought jurors might conceivably know about or might believe that they knew about. This is a subjective analysis; we attempted to err on the side of concluding that jurors might know about an invention.

255 The fact of litigation itself may give rise to an indication that some invention was achieved, but most cases could likely be arranged to limit this suggestion, as well as avoiding a signal as to what the actual invention was, as discussed in the following paragraph. 
juror's attention somewhat. This potential focus is unavoidable, but it is not as problematic as it might initially appear. First, a substantial degree of focus is appropriate for the non-obvious determination-the determination is supposed to be based on a person in the field, often working on a particular problem. Second, the focus appears worse due to our own hindsight biaswe know what the invention is, so it appears that the prior art, problem, and knowledge irreducibly lead toward it. Third, the litigation may itself indicate to some jurors that some invention was achieved, but by not informing the jury of the particular invention, the bias will be reduced. The responses to the scenarios used in this study support this conclusion: respondents routinely found inventions non-obvious even when explicitly presented with focused prior art and problem that the inventor was working on-about three-quarters of the participants in the foresight condition in each scenario found the invention non-obvious. ${ }^{256}$

A final concern is that jurors will not be able to determine whether a complex technology invention is obvious because they are not experts in the field. This problem, however, already exists in current non-obvious decisions, and is not exacerbated by this proposal. Further, this concern should be reduced by a greater focus on evidence concerning the skill and knowledge of a person having ordinary skill in the art.

In addition to reducing the hindsight bias in patent law, this proposal offers another significant advantage over current patent doctrine. It eliminates the need for application of the controversial suggestion, teaching, or motivation doctrine. The suggestion doctrine's objective is to prevent picking and choosing various elements from the prior art to construct an invention in hindsight. If hindsight knowledge of the invention is avoided, however, simply presenting a juror with the analogous relevant prior art places him or her in the appropriate position to judge whether an invention was non-obvious.

Bifurcation could help ameliorate the hindsight effect in the other doctrinal areas of concern as well. Although different issues may need to be separated in each instance (e.g., the alleged equivalent element for the doctrine of equivalents), application of this method could help to mitigate the hindsight bias in each of the situations identified. The non-obvious trial proposal described here is not perfect, but it is a far better solution to the hindsight bias problem than current patent litigation and jurisprudence. ${ }^{257}$

256 See supra Part III.B.

257 Other potential methods for ameliorating the hindsight bias include the use of expert juries and court reorganization. Either option could be implemented in combination with the recommendations proposed here. Both additional methods are based on the fact that hindsight bias studies indicate that the bias is worse for individuals unfamiliar with a task than for individuals familiar with the same task. Supra Part 


\section{CONCLUSION}

The study reported here has significant implications for patent law and policy. The results indicate that the hindsight bias has a greater and more pervasive impact on non-obvious decisions and on patent law generally than previously anticipated. The hindsight effect is projected to hold whether the decision-maker is a judge, jury, or (to a slightly lesser extent) PTO examiner. Jury instruction and court-developed precedent to avoid the hindsight bias do not provide relief. The hindsight effect is particularly troublesome for patent litigation. As it is the close non-obvious cases concerning valuable patents that are expected to be litigated, ${ }^{258}$ even a slight hindsight bias could result in a substantial number of incorrect patent decisions concerning valuable patents. ${ }^{259}$ Reform of non-obvious doctrine therefore appears necessary. A system that routinely results in outcomes based on cognitive error and biases, yielding stochastic patent decisions that contradict the rule of law, is neither equitable nor efficient, and is hardly a sound basis for intellectual property rights that help shape industry and markets.

III.C.2-3. Expert juries could be familiar with both the technology and the non-obvious determination. This change, however, would face Seventh Amendment difficulties, as well as practical problems concerning recruiting enough experts and their relationship to the PTO (a deep source for technological experts). The court reorganization suggestion is based on the reality that district court judges generally are unfamiliar with non-obvious decisions. Supra Part III.C.2. Perhaps consolidating patent cases (or patent validity cases, or patent validity cases with a non-obvious issue) in a single district court would make certain district court judges more familiar with the task and consequently ameliorate the hindsight bias. Candidate courts here include the District Court for the District of Columbia, which hears some appeals from the PTO, or the U.S. Court of International Trade, which is made up of Article III judges, has parallel jurisdiction to district courts in patent litigation, and is already within the Federal Circuit. Along these lines, a bill has been introduced in Congress to create a pilot program to increase judicial expertise on patent cases for certain district court judges and allow other judges to transfer their patent cases to the "patent expert" judges. H.R. 5418, 109th Cong. (2d Sess. 2006). A significant problem with both suggestions is that, as discussed, familiarity only slightly reduces the bias. Supra Part III.C.2-3.

258 John R. Allison et al., Valuable Patents, 92 GEO. L.J. 435, 439 (2004) (arguing that litigated patents are expected to be valuable ones); see generally George L. Priest \& Benjamin Klein, The Selection of Disputes for Litigation, 13 J. LEGAL STUD. 1 (1984) (presenting empirical evidence that it is generally close disputes that are litigated).

259 Because litigants are expected to be equally susceptible to the hindsight bias as judges or jurors, this statement cannot be made definitively. The patents litigated would still be expected to be valuable, but it is likely that many litigated patents only appear to present close non-obvious issues in hindsight. The extent of this effect will depend on the distribution of how "close" non-obvious cases are. I am grateful to Douglas Lichtman for pointing this out. 
The finding that the non-obvious requirement may be applied too stringently in many cases indicates that perhaps too many patents are being rejected or invalidated on obviousness grounds. Such a conclusion runs counter to the current dominant view of patent decisions. The lion's share of analysts (including the Federal Trade Commission, the National Research Council, and many patent and economic scholars) contend that courts and the PTO do not evaluate the non-obvious requirement stringently enoughthat too many obvious patents are granted and upheld. ${ }^{260}$ A number of these critiques are based on identification of seemingly obvious patented inventions. ${ }^{261}$ This study reveals that the general patenting criticism likely is impacted by the hindsight bias and that certain of these inventions probably only appear obvious in hindsight. ${ }^{262}$ The overriding call for strengthening

260 See, e.g., FED. TRADE COMM'N, supra note 5, ch. 4, at 8-19 (criticizing a low standard for application of the non-obvious requirement and citing the testimony of many patent and economic scholars for the same); NATIONAL RESEARCH COUNCIL, supra note 5, at 87-95 (criticizing lenient non-obvious standards, particularly for business method and biotechnology patents); IP Professors' Amici Brief, supra note 5, at 10 (brief of twenty-four intellectual property law professors arguing that Federal Circuit case law sets too low a non-obvious standard); JAFFE \& LERNER, supra note 6, at 32-35, 75, 119-23, 145-49 (criticizing the PTO for granting patents on obvious inventions); Shapiro, supra note 6, at 1018 (noting that complaints regarding the PTO "typically allege that the [PTO] issues many questionable patents" including those that were "obvious at the time the patent application was filed"); Edited \& Excerpted Transcript of the Symposium on Ideas into Action, supra note 6, at 1056 (comment by Mark Myers calling for "[r]einvigorat[ion of] the nonobvious standard" and noting that panelists "believe that there has been some lowering of the bar of that standard"); Merges, supra note 6, at 598 (noting that "[t]he easiest way to raise standards [at the PTO], conceptually, is to tighten the nonobviousness requirement of section 103," but acknowledging that this would be difficult); Parker, supra note 6, at 305-07 (arguing that the PTO has recently granted a number of obvious patents); Barton, supra note 6, at 477-78 (arguing that the nonobvious standard applied by the PTO and courts today is not as strict as that articulated by the Supreme Court in Graham); Thomas, supra note 6, at 773 (criticizing the Federal Circuit for lowering the non-obvious standard); Lemley \& O'Brien, supra note 6, at 301 (criticizing PTO leniency in issuing obvious patents in software); Thomas, supra note 6 (discussing problems at the PTO in conducting non-obvious analyses). Cf. Lesser \& Lybbert, supra note 6, at 382 (arguing, based on empirical study, that patentability standards have not declined over time).

${ }^{261}$ See, e.g., JAFFE \& LERNER, supra note 6, at 32-33, 75, 121-22, 145-46 (criticizing the granting of patents on a peanut butter and jelly sandwich, on Amazon's one-click ordering process, on a television remote control combining two known features, and on infinitely lived options); Parker, supra note 6, at 305-07 (criticizing the PTO for recently granting obvious patents on inventions such as the peanut butter and jelly sandwich and the use of a laser pointer to exercise a cat).

${ }^{262}$ Certainly some of the seemingly silly patents granted by the PTO are obvious, but anecdotal identification of several errors does not establish a problem generally or render less critical the consequences of the results reported here. 
the non-obvious standard may result in part from the critics' own unconscious cognitive biases.

This is not to say that the appropriate number of patents is granted. Despite the hindsight bias, a number of factors may result in too many patents being issued or upheld against invalidity challenges. These factors include the presumption of patentability at the PTO, ${ }^{263}$ institutional pressures favoring patentability at the $\mathrm{PTO},{ }^{264}$ the presumption of validity that adheres to issued patents, ${ }^{265}$ and potential jury and judge deference to experts, as well as problems in applying the non-obvious requirement. On a wider viewscreen, other dynamics must be taken into account to determine the socially and economically optimal level of patenting, including efficiently incentivizing innovation, ${ }^{266}$ optimizing market competition, ${ }^{267}$ the importance of patent rights in various industries, ${ }^{268}$ and concerns over inefficient patent thickets ${ }^{269}$ and anti-commons, ${ }^{270}$ as well as the proper non-

263 FED. TRADE COMM'N, supra note 5, Executive Summary, at 9; MANUAL OF PATENT EXAMINING PROCEDURE § 2142.

264 See, e.g., Shubah Ghosh \& Jay Kesan, What Do Patents Purchase? In Search of Optimal Ignorance in the Patent Office, 40 Hous. L. REV. 1219, 1246 (2004) (accusing the PTO of "grant[ing] too many patents as a result of internal incentives or the lack of internal checks")

26535 U.S.C. $\S 282$ (Supp. 2002).

266 See, e.g., Merges \& Nelson, supra note 225; Rebecca S. Eisenberg, Patents and the Progress of Science: Exclusive Rights and Experimental Use, 56 U. CHI. L. REV. 1017 (1989).

267 Gary L. Reback, Patently Absurd: Too Many Patents Are Just as Bad for Society as Too Few, FORBES, June 24, 2002, available at http://www.forbes.com/asap/2002/0624/044.html (discussing the economic ramifications of the PTO's “policy of patent proliferation"); Evan P. Schultz, Too Many Patents?, LEGAL TIMES, Mar. 21, 2002 (discussing the economic and competition effects of patenting); Merges, supra note 127 (discussing the competitive effects of too many patents).

268 See, e.g., FED. TRADE COMM'N, supra note 5, ch. 3; Dan L. Burk \& Mark A. Lemley, Policy Levers in Patent Law, 89 VA. L. REV. 1575, 1577, 1586 (2003); Qin Shi, Patent System Meets New Sciences: Is the Law Responsive to Changing Technologies and Industries?, 61 N.Y.U. ANN. SURV. AM. L. 317 (2005).

269 See, e.g., Burk \& Lemley, supra note 268; Arthur K. Rai \& Rebecca S. Eisenberg, The Public Domain: Bayh-Dole Reform and the Progress of Biomedicine, 66 L. \& CONTEMP. ProB. 289, 297-98 (2003); Carl Shapiro, Navigating the Patent Thicket: Cross Licenses, Patent Pools, and Standard Setting, 1 InNOVATION POLICY \& ECON. 119 (2001).

270 See, e.g., Rai \& Eisenberg, supra note 269, at 297-98; Burk \& Lemley, supra note 268; Michael A. Heller \& Rebecca S. Eisenberg, Can Patents Deter Innovation? The Anticommons in Biomedical Research, 280 SCIENCE 698 (1998). 
obvious standard. ${ }^{271}$ This study does, however, reveal that the hindsight bias plays an important and relatively over-looked part of this puzzle, and that its effects must now be integrated into the vigorous debate over the appropriate non-obvious standard and level of patenting.

That too many patents may be issued does not resolve the hindsight problem or render it less critical. There is no reason to expect a one-to-one correspondence between inventions that benefit from factors that over-favor patenting and inventions that suffer in patent likelihood due to the hindsight bias. Different forces, such as the complexity of the technology, the level of skill in the art, the maturity of the field, and the contours of patenting in the area, among others, are expected to impact the influence of these various factors differently. Even if we assume that too many patents are issued in spite of the hindsight bias, the hindsight bias still results in the wrong patents being issued and denied. To the extent that the non-obvious standard should be strengthened, this study reveals that achieving such a goal is more complex and nuanced than previously understood. The relationship between non-obvious doctrine and actual non-obvious decisions is mediated by the hindsight bias. Any recommendation for an improved legal regime needs to take into account this thorny interaction.

Rather than being the last word on the hindsight bias in patent law, this study hopefully opens our minds to the need to better understand the behavioral and cognitive influences that impact the non-obvious and other patent decisions. Concerning the hindsight bias alone, this study points to the need for further research on its contours, how it affects different decisionmakers, and how it affects different types of patent decisions. Simply identifying patent deficiencies is not enough; without greater recognition of how patent decisions are actually made, proposed solutions are just as likely to fail as they are to solve their targeted problem.

These insights come at a particularly vital time in patent law, as Congress is currently considering the most widespread patent reform in over a generation. This study breaks down some commonly held misbeliefs about patent doctrine and highlights the need to better comprehend the factors that affect patent decisions in order to produce appropriate reform. Responding to these issues correctly is crucial-it will affect not only patent law and policy, but also technological advances, market competition, and the economy as a whole.

271 See supra note 259. 


\section{APPENDIX A}

\section{HINDSIGHT BIAS STUDY SCENARIOS}

Following are copies of the baseball and fishing lure scenarios used in this study. The hindsight condition scenarios are provided. The foresight condition scenarios were identical, except that the last sentence of the story (disclosing the invention) was not included. The debiasing condition scenarios were identical to the hindsight ones, except that the first and second questions on the questionnaire included model jury instructions informing the participant of the hindsight bias, warning about it, and advising him or her not to use hindsight in answering the questions (these instructions are described in footnote 59 and the accompanying text of this Article). Material in " \{\} " marks is added for the reader and was not part of the actual surveys. 


\section{\{Baseball scenario, hindsight condition\}}

This study includes a one-page story and related questions. Please read the following story and then answer the questions on the next page as best as you can.

\section{Curveball}

This scenario involves instructional materials for teaching people how to throw different baseball pitches. Baseball pitchers throw baseballs in different manners so that they will move differently in order to make it more difficult for a batter to hit the ball. In addition to standard fastballs, pitchers also throw curveballs, sliders, change-ups, and a variety of other pitches, each of which moves in a different manner. The trick to throwing these pitches is to hold the ball differently in your hand and to move your wrist differently as you release the ball.

Baseball pitching instruction is a big business. A wide variety of instructional materials exist in order to teach people, particularly teenagers, how to throw different pitches. These materials include instructional videos showing how to hold and release different pitches, articles and books which describe how to hold and release different pitches, cards which show a picture of a hand holding a baseball in the proper way to make a certain pitch, plastic baseballs with indentations showing how to hold the ball to make a certain pitch, and baseball workshops where people can go to learn different pitches.

Mike works in the Baseball Instruction division of PlayBall Inc., a sporting goods company that markets a variety of instructional baseball materials. Mike's job is to develop new baseball instruction materials; his knowledge and skill in developing new baseball instruction materials is about ordinary for people working in the field.

Mike's supervisor has told him that PlayBall would like to develop and market a new pitching instruction product. The supervisor says that the indented plastic baseballs and baseball workshops provide much better instruction than other materials because the student is actually holding the baseball as s/he learns how to throw a pitch. However, both of these options have problems. The plastic baseballs do not give the feel or action of real baseballs, and you need a whole set of them to throw different pitches. The workshops provide the greatest instruction, but are very expensive compared to the other materials. Mike's supervisor asks Mike to try to come up with an 
inexpensive product that will do a better job of teaching new pitches than the videos, articles and books, cards, and plastic baseballs on the market.

Mike comes up with the idea of placing ink markings on an actual baseball indicating how to hold the ball for various pitches, creating an inexpensive instructional device that allows the student to actually hold the baseball while learning. 


\section{\{Fishing lure scenario, hindsight condition\}}

This study includes a one-page story and related questions. Please read the following story and then answer the questions on the next page as best as you can.

\section{Gone Fishing}

This scenario involves fishing lures. Fishing lures are artificial bait attached to the end of a fishing line, used to attract and catch fish. Lures offer an advantage over live bait (such as worms, insects, or small fish) because they will not spoil and are more likely to stay attached to a fishing line in water. On the other hand, if a fish realizes that a lure is artificial, it will not take the bait, and will not be caught.

Making fishing lures is a widespread hobby and a big business. Many people and companies try to make lures that are better at attracting and catching fish, either for their own enjoyment or to sell for profit. Lures generally have two parts: a body part and a hook part. The body is usually made of wood, plastic, feathers, or animal hair. The most important lure elements for attracting fish are its appearance and its odor. Fish are more likely to be attracted to lures whose look and movement best simulates live bait, and whose odor and taste seem most like live bait.

One problem with fishing lures is that even if they look and smell real enough for a fish to bite, once the fish bites it will realize the lure is artificial, and may spit it out before a fisherman realizes s/he has a fish and can pull on the line to set the hook. Therefore, lure makers work on ways to get a fish to keep the lure in its mouth longer, for instance by giving it a natural taste.

It has long been known that fish are attracted to a salty smell and flavor. An article titled "Touch Up Your Lures," published in 1987, suggested adding fish attractants with "the flavor or odor of natural bait" to lures. In 1990 an inventor got a patent on a lure made out of squirrel hair with yeast and salt baked in so as to emit an odor attractive to fish. The Great Book of Black Bass, published in 1998, noted that fish could actually "taste" bait before biting, and recommended the use of salted pork rind as bait. Somewhat similarly, an entry titled "Salted Wonder for Trout" in the 2001 Field Sports Almanac describes using salted minnows as bait, noting, "real monster trout will take salt-flavored minnows as if they are going out of style." 
James is an avid fisherman. He also likes to make his own lures, and has done so for some time; his knowledge skill in making lures is about ordinary for people working with lures. James was frustrated with existing salty lures because they all either lost their salty taste in water (such as the squirrel hair lure) or would spoil (such as the pork rinds and minnows), or both. James decided to try to make a lure with an odor and taste that would attract fish, but that would not lose its odor in water or spoil.

James comes up with the idea of adding salt into a plastic lure as it is made, creating a salty lure that will not spoil or lose its odor in water. 


\section{\{Fishing lure questionnaire, hindsight condition\}}

Following are some questions about the above story. Based on the information provided in the story, please answer the questions as best you can.

1. How likely was it that James \{baseball questionnaire: "Mike"\} would figure out a solution to the problem he was working on?

1 not at all likely
3

equally likely

to happen or not
5

$6 \quad 7$

extremely likely

2. In light of the existing knowledge about fishing lures (baseball questionnaire: "instructional materials" $\}$ and information in the scenario above, do you think a solution to the problem was obvious to a person with ordinary skill in the field of fishing lures \{baseball questionnaire: "baseball instruction"\} at the time James \{baseball questionnaire: "Mike"\} was working on the problem?

Yes No

3. How confident are you of your answer to Question 2 above? $\begin{array}{lllllllllll}0 \% & 10 \% & 20 \% & 30 \% & 40 \% & 50 \% & 60 \% & 70 \% & 80 \% & 90 \% & 100\end{array}$ $\%$

not at all confident

Moderately confident absolutely confident

4. What is your gender?

$\begin{array}{ll}\text { Female } & \text { Male } \\ -18-29 & \\ -30-49 \\ 50-69 & -70 \text { or older }\end{array}$

6. What is the highest education you completed? No high school

5. What is your age? Some high school High school graduate Some college or a 2-year college 4-year college degree Graduate degree (e.g., M.A./Ph.D./M.D./J.D.)

7. What is your racial/ethnic background? White/Caucasian (non-Hispanic) Black/African-American (non-Hispanic) Hispanic Asian Other 


\section{APPENDIX B}

\section{SECONDARY CONSIDERATION EVIDENCE}

Table B-1. Reported Non-Obvious Decisions, July 2004-Dec. 2005

\begin{tabular}{|l|c|c|c|}
\hline \multicolumn{1}{|c|}{ Holding } & $\begin{array}{c}\text { Total Reported } \\
\text { Decisions }\end{array}$ & $\begin{array}{c}\text { Federal Circuit } \\
\text { Decisions }\end{array}$ & $\begin{array}{c}\text { District Court } \\
\text { Decisions }\end{array}$ \\
\hline Obvious & 19 & 11 & 8 \\
\hline Non-Obvious & 34 & 10 & 24 \\
\hline Remand & 9 & 9 & N/A \\
\hline $\begin{array}{l}\text { Summary } \\
\text { Judgment Denied }\end{array}$ & 18 & 1 & 5 \\
\hline $\begin{array}{l}\text { Preliminary } \\
\text { Injunction Phase- } \\
\text { Likely Obvious }\end{array}$ & 6 & 0 & 5 \\
\hline $\begin{array}{l}\text { P.I. or T.R.O. } \\
\text { Phase-Likely } \\
\text { Non-Obvious }\end{array}$ & 5 & 0 & 2 \\
\hline Split Decisions & & & \\
\hline Total & 2 & 31 & 62 \\
\hline
\end{tabular}

a Two decisions (both by district courts) were split in their holdings on various claims or involved different holdings on multiple patents at issue. These were (1) Network Appliance, Inc. v. Bluearc Corp., 374 F. Supp. 2d 825 (N.D. Cal. 2005) (one patent claim held obvious, another claim held non-obvious), and (2) Abbott Labs. v. Andrx Pharms., Inc., 2005 U.S. Dist. LEXIS 10846 (N.D. Ill. June 3, 2005) (one patent held likely non-obvious at preliminary injunction phase, two other patents held obvious).

b Where there were multiple reported non-obvious decisions from the same litigation, only the most recent (authoritative) decision was taken into account. Except for the Abbott Labs case discussed in the footnote above, none of the decisions concemed multiple reported decisions from the same litigation. 
Table B-2. Decisions Analyzing Secondary Consideration Evidence (41 of the 93 total cases reported in Table B-1)

\begin{tabular}{|l|c|c|c|}
\hline & $\begin{array}{c}\text { Total Reported } \\
\text { Decisions }\end{array}$ & $\begin{array}{c}\text { Federal Circuit } \\
\text { Decisions }\end{array}$ & $\begin{array}{c}\text { District Court } \\
\text { Decisions }\end{array}$ \\
\hline $\begin{array}{l}\text { Changed } \\
\text { Outcome from } \\
\text { Obvious to Non- } \\
\text { Obvious }\end{array}$ & 2 & 0 & $2^{\mathrm{c}}$ \\
\hline $\begin{array}{l}\text { Merely Further } \\
\text { Support of Non- } \\
\text { Obvious }\end{array}$ & 25 & 2 & 23 \\
\hline $\begin{array}{l}\text { Claims } \\
\text { Ultimately Held } \\
\text { Obvious }\end{array}$ & 14 & 6 & 8 \\
\hline $\begin{array}{l}\text { Analyzed in } \\
\text { Summary } \\
\text { Judgment } \\
\text { Decisions }\end{array}$ & 10 & N/A & 10 \\
\hline $\begin{array}{l}\text { Analyzed in } \\
\text { P.I./T.R.O. } \\
\text { Decisions }\end{array}$ & 6 & 1 & 5 \\
\hline
\end{tabular}

c See supra Part IV.A for discussion of these cases. 
Table B-3. Types of Secondary Consideration Evidence in the 4l Table B-2 Cases

\begin{tabular}{|c|c|c|c|}
\hline & $\begin{array}{l}\text { Total Reported } \\
\text { Decisions } \\
\text { (percent of } \\
\text { non-obvious } \\
\text { decisions) } \\
\end{array}$ & $\begin{array}{c}\text { Federal Circuit } \\
\text { Decisions }\end{array}$ & $\begin{array}{l}\text { District Court } \\
\text { Decisions }\end{array}$ \\
\hline $\begin{array}{l}\text { Commercial } \\
\text { Success }\end{array}$ & $\begin{array}{c}31 \\
(33 \%) \\
\end{array}$ & 7 & 24 \\
\hline Long Felt Need & $\begin{array}{c}22 \\
(24 \%)\end{array}$ & 3 & 19 \\
\hline $\begin{array}{l}\text { Unexpected } \\
\text { Results }\end{array}$ & $\begin{array}{c}12 \\
(13 \%)\end{array}$ & 2 & 10 \\
\hline Failure of Others & $\begin{array}{c}11 \\
(12 \%)\end{array}$ & 0 & 11 \\
\hline Copying & $\begin{array}{c}11 \\
(12 \%)\end{array}$ & 2 & 9 \\
\hline Skepticism & $\begin{array}{c}6 \\
(6 \%)\end{array}$ & 0 & 6 \\
\hline Licensing & $\begin{array}{c}5 \\
(5 \%)\end{array}$ & 2 & 3 \\
\hline Acclamation & $\begin{array}{c}5 \\
(5 \%)\end{array}$ & 0 & 5 \\
\hline $\begin{array}{l}\text { Simultaneous } \\
\text { Invention by } \\
\text { Others } \\
\text { d }\end{array}$ & $\begin{array}{c}4 \\
(4 \%)\end{array}$ & 1 & 3 \\
\hline
\end{tabular}

d Unlike the other types of secondary consideration evidence, this type is introduced as evidence of an invention's obviousness. All decisions reporting introduction of evidence of simultaneous invention by others included other types of secondary consideration evidence as well. 
